\title{
ARTÍCULO
}

\section{Fisuras en la Protección de los Derechos de la Infancia Cracks in the Protection of the Rights of the Child}

\author{
Teresa Picontó Novales \\ Área de Filosofía del Derecho \\ Universidad de Zaragoza
}

Fecha de recepción: 12/01/2016 | De aceptación: 30/05/2016 | De publicación: 22/06/2016

\begin{abstract}
RESUMEN
La Convención sobre los Derechos del Niño de las Naciones Unidas con su aprobación en 1989 supuso un avance en la concepción de los derechos de los niños y sin duda, un importante desarrollo de los derechos de la infancia y de la adolescencia en muchos países del mundo. Más de veinticinco años después, ha llegado el momento de cuestionar el discurso de los derechos del niño tal y como cristalizó en la Convención y ello, por varias razones. En primer lugar, porque hay otras infancias u otras concepciones de la infancia que han quedado en los márgenes de la concepción hegemónica de la infancia recogida en la Convención, bien por motivos culturales, sociales, antropológicos, etc. En segundo lugar, y no por ello menos importante, porque es ya ineludible incorporar una decidida perspectiva de género en el discurso de los derechos de los niños a la vista de la realidad social, económica y cultural diferenciada y muchas veces discriminatoria para las niñas en ámbitos como el familiar, sanitario, educativo, laboral o de justicia juvenil, entre otros. Y porque, en los últimos más de quince años, han ido apareciendo interesantes estudios e investigaciones en el ámbito de la sociología de la infancia, de la antropología de la infancia, de la historia de la infancia, etc.., que plantean con acierto algunas de las carencias y deficiencias más importantes de la Convención sobre los Derechos del Niño tanto a nivel del discurso teórico como en el de la praxis que, cuando menos, requieren ser tenidos en cuenta en una reflexión que permita a la larga abrir un diálogo con algunas de estas corrientes teóricas y empíricas. Siendo que además muchas de ellas van de la mano de los movimientos sociales de la infancia y de la adolescencia. Esfuerzo que ya se ha visto en parte recogido progresivamente en la interpretación de la Convención -que ha ido cambiando a lo largo de los años-; y que a la larga acabará por revertir en la mejora de los derechos de los niños y las niñas en un mundo globalizado como en el que vivimos.
\end{abstract}

PALABRAS CLAVE

Convención sobre los Derechos del Niño. Concepciones de la infancia. Género y derechos de la infancia y la adolescencia. Diversidad cultural y derechos de la infancia. Avances y omisiones en la protección de los derechos de la infancia.

\section{ABSTRACT}

The adoption of the United Nations Convention on the Rights of the Child in 1989 represented a significant advance in the conception of children's rights and in the development of children's rights in many countries in the world. More than twenty-five years later, the time has come to question the discourse of the rights of the child as set out in the Convention for several reasons. In the first place, there are other conceptions of childhood which have remained on the margins of the hegemonic conception of childhood given in the Convention, whether for cultural, social or anthropological reasons. In the second place, and no less important, it is now unavoidable to incorporate a definite gender perspective in the discussion of the children's rights in view of the social, economic and cultural reality which is different and frequently discriminatory for girls in areas such as the family, health, education, youth justice and employment, among others. Another reason is that over the past fifteen years several interesting studies have appeared in the area of childhood (anthropology, sociology, history, etc.), which correctly point out some of the most significant omissions and deficiencies in the Convention on the Rights of the Child on both a theoretical and a practical level which, at the very least, need to be taken into account in any reflection leading to a dialogue between these theoretical and empirical currents. Many of these currents go hand in hand with social movements of children's rights. Such efforts have already been seen in part to be progressively integrated in the interpretation of the Convention - which has been changing over the years-; and which in the long run will have an impact on the improvement of the rights of boys and girls in the globalized world in which we live.

KEY WORDS

Convention on the Rights of the Child. Conception of childhood. Gender and children's rights. Cultural diversity and children's rights. 
otros. Por último, también, a causa de que en los últimos quince años han ido apareciendo

Sumario: Introducción. 1.- La Convención de 1989: Un instrumento crucial en el reconocimiento y garantía de los derechos de la infancia y la adolescencia. 2. El concepto de infancia en la Convención y la diversidad cultural y social: Otras infancias. 3.- Los derechos de la infancia en clave de género. 4.- Conclusiones.

\section{Introducción}

La Convención sobre los Derechos del Niño de las Naciones Unidas con su aprobación en 1989 supuso un avance en la concepción de los derechos de los niños y, sin duda, un importante desarrollo de los derechos de la infancia y de la adolescencia en muchos países del mundo.

Transcurridos más de veinticinco años desde su aprobación, ha llegado el momento de reflexionar sobre el discurso de los derechos del niño tal y como cristalizó en la Convención y ello, por varias razones. En primer lugar, porque hay otras infancias u otras concepciones de la infancia que han quedado en los márgenes de la concepción hegemónica de la infancia recogida en la Convención, bien por motivos culturales, sociales, antropológicos, etc. En segundo lugar, y no por ello menos importante, porque es ya ineludible incorporar una decidida perspectiva de género en el discurso de los derechos de la infancia; a la vista de la realidad social, económica y cultural diferenciada y muchas veces discriminatoria para las niñas en ámbitos como el familiar, sanitario, educativo, laboral o de justicia juvenil, entre interesantes estudios e investigaciones en el ámbito de la sociología de la infancia, de la antropología de la infancia, de la historia de la infancia, etc., que plantean con acierto algunas de las carencias y deficiencias más importantes de la Convención sobre los Derechos del Niño ${ }^{l}$, tanto a nivel del discurso teórico como en el de la praxis, que cuando menos requieren ser tenidos en cuenta en una reflexión que permita abrir un diálogo con algunas de estas corrientes teóricas y empíricas. Muchas de ellas, por otra parte, van de la mano de los movimientos sociales de la infancia y de la adolescencia y los avances realizados ya se han visto en parte recogidos en la interpretación de la Convención ${ }^{2}$-que ha ido cambiando a lo largo de los años-; y que a la larga acabará por revertir en la mejora de los derechos de los niños y las niñas. La incorporación de estas perspectivas facilitaría "abrir" la Convención a esas otras concepciones de la infancia existentes para conseguir que niños y niñas se vieran reflejados mejor en la misma. Pudiendo apropiarse y beneficiarse entonces de sus derechos y ello porque habríamos logrado que

\footnotetext{
1 Vid. P. Ronfani, "I Diritti dei bambini: vecchie e nuove questioni”, en Sociologia del Diritto (2013) n 2, p. 117-122.

${ }^{2}$ Así, por ejemplo, la evolución en la interpretación del principio rector del "superior interés del niño" del art. 3 de la Convención. Cuenta de ello, entre otras, es la Observación General $n^{\circ} 14 \mathrm{del}$ Comité de los Derechos del Niño, del 29 de mayo de 2013, sobre el derecho del niño a que su intéres superior sea una consideración primordial.
} 
Cuadernos Electrónicos de Filosofía del Derecho

los derechos de los niños y las niñas respondan a sus experiencias de vida.

Al hilo de lo que se acaba de plantear, este artículo se estructura en tres partes. En la primera parte del trabajo se va a analizar como el largo proceso de especificación y reconocimiento de los derechos de la infancia constituye un logro histórico, legal e internacional que culmina en la Convención sobre los Derechos del Niño de 1989 de las Naciones Unidas. Ahora bien, este instrumento es también producto de una determinada concepción de la infancia, la llamada infancia hegemónica, y del contexto de un orden social "ideal" desde el que se define la posición de los niños y de las niñas; así como el reparto de papeles entre los agentes encargados de proteger y garantizar sus derechos e intereses (el Estado y la familia, fundamentalmente). Es por ello que en la segunda y tercera parte de este artículo me interesa sacar a la luz los motivos por los que un instrumento como el de la Convención sobre los Derechos del Niño presenta, junto a sus logros, importantes carencias y limitaciones. Para lo cual analizaré críticamente el discurso de los derechos del niño tal y como quedó cristalizado en la Convención, a la luz de una renovada perspectiva cultural, social y antropológica $\mathrm{y}$, por último, desde una perspectiva de género.
1.- La Convención de 1989: Un instrumento crucial en el reconocimiento y garantía de los los derechos de la infancia y la adolescencia.

Desde finales del siglo XVIII y principios del XIX se pueden ya rastrear en el sistema político de protección de la infancia, tanto en Europa como en EE.UU, los primeros esbozos de lo que acabará por desembocar en los sistemas actuales de protección y de reconocimiento de los derechos de los menores. Ya en el siglo XVII se va a generalizar una concepción moral de la infancia a la que le preocupa la fragilidad y debilidad del niño más que cualquier otro aspecto. Paralelamente, cambian también las relaciones de la sociedad y de la familia con la infancia. Al concentrarse la familia alrededor del niño resultará reforzada comenzando a dibujarse las líneas de lo que será la familia patriarcal. Concretamente, a finales del siglo XIX aparecen unas sociedades protectoras de la infancia tanto en Europa como en EE.UU, con el objetivo de proteger a la infancia en peligro, esto es, a los niños víctimas de maltrato o a los niños que se encuentran en una situación de peligro moral, dejando para el Estado la competencia de los niños huérfanos o abandonados. Los protagonistas de estas actuaciones fueron fundamentalmente médicos e higienistas. Fueron ellos quienes desde 
Cuadernos Electrónicos de Filosofía del Derecho

sus cargos públicos impulsaron unas leyes defensoras de los derechos de la infancia ${ }^{3}$.

Más concretamente, los grandes filántropos y sus asociaciones se dedicaron a la tarea salvadora de la infancia, esto es, a su moralización y reeducación; así como a la iniciativa legislativa o de reforma de la legalidad vigente. En cualquier caso, lo cierto es que la iniciativa particular precedió a la del Estado en la mayoría de los casos (Alemania, EE. UU, Francia, Inglaterra, España, etc.). En muchos de estos países, el Estado lo que hizo fundamentalmente fue apoyar y después secundar las acciones del movimiento filantrópico, muchas veces limitándose a regular legislativamente procedimientos $\mathrm{y}$ actuaciones que ya estaban funcionando en la práctica. Ahora bien, este proceso de convergencia de intereses, estatal y privado, estuvo sembrado de tensiones y fue de una gran complejidad. A la postre del mismo se produjo una red de complicidad y poco a poco la acción del Estado fue ganando protagonismo.

\footnotetext{
${ }^{3}$ Me he ocupado más extensamente de estas cuestiones en $\mathrm{T}$. Picontó Novales, La protección de la infancia: Aspectos sociales y jurídicos, Zaragoza, Egido Editorial, 1996, p. 20ss. Vid. también, T. Picontó Novales, "Presupuestos y avance de los mecanismos jurídicos de protección de la infancia en el siglo XIX"; e I. Campoy Cervera, "El desarrollo de un modelo de protección de los niños en el siglo XIX" en G. Peces-Barba, edtr., Historia de los Derechos Fundamentales, Madrid, Dykinson, 2007, Tomo III, Volumen II, Libro 1, Cap. XXX, , p. 533-568 y p. 471-532 respectivamente.- Vid. también: I. Ravetllat Ballesté, Aproximación histórica a la construcción sociojurídica de la categoría infancia, Valencia, Editorial Universitat Politècnica de València, 2015, p. 1-3
}

Es así como aparece un programa de reorganización de la asistencia a la infancia caracterizado por un reforzamiento del sentimiento familiar, cuyo modelo es el de la familia patriarcal. De este modo, la familia deja de ser únicamente una institución jurídico-privada para asumir una función moral y política. Concretamente, la familia se convierte en la matriz a partir de la cual se desencadena toda la política de control de la infancia peligrosa y en peligro, política a la que confluirán, primero, y terminarán por aliarse después, el asociacionismo filantrópico y la entidad estatal. Cuando los intereses estatales y los del movimiento filantrópico convergen en una misma línea de actuación y aúnan sus fuerzas, los instrumentos en los que se apoyan serán fundamentalmente las leyes sanitarias, educativas y de protección de menores, así como en la creación de unos tribunales especiales para niños ${ }^{4}$

Este proceso acabará por desembocar en la concepción de que los niños y adolescentes tienen derechos e intereses dignos de ser protegidos y garantizados $^{5}$. Es así como surgen las primeras

\footnotetext{
${ }^{4}$ Otro antecedente histórico lo constituye el establecimiento de unos tribunales especiales de justicia juvenil (en algunos países). Si los contemplanos desde la óptica de los derechos de los niños esta iniciativa de la creación de unos tribunales de justicia juvenil resulta cuando menos ambigua tal y como lo han señalado, entre otros: S. Marks y A. Clapham, $1^{\mathrm{a}}$ ed., International Human Rights Lexicon, Oxford, Oxford University Press, 2005, p. 19-20; vid. también, M. J. Bernuz, De la protección de la infancia a la prevención de la delincuencia, Zaragoza, Justicia de Aragón, 1999, p. 125-210

${ }^{5}$ Vid. I. Campoy Cervera, La fundamentación de los Derechos de
} 


\section{CEFD}

Cuadernos Electrónicos de Filosofía del Derecho

leyes de protección de la infancia, aprobadas a finales del siglo XIX y principios del XX, y se verá reflejado en la Declaración sobre los derechos del niño de 1924, donde se establece que "la humanidad debe a los niños lo mejor que pueda darles"; principio que la Convención sobre los derechos del niño de 1989 tradujo en derechos y garantías encaminados a realizar específicamente los derechos de los menores, en el sentido más amplio del término. Concretamente la Convención sobre los derechos del niño fue aprobada el 20 de noviembre de 1989 y entro en vigor el 2 de septiembre de 1990 y ha sido ratificada por la práctica totalidad de los Estados con la ausencia significativa de USA ${ }^{6}$. Este reconocimiento implica también asegurar su bienestar y sentar como máxima prevalente en todo tipo de actuaciones e intervenciones realizadas con los menores el principio del "interés superior del niño". Este reconocimiento internacional de los derechos de la infancia y de la adolescencia ha dado lugar también a su

los Niños. Modelos de reconocimiento y protección, Madrid, Dykinson, 2006, p. 977-1002.

${ }^{6}$ Sobre la evolución en el reconocimiento jurídico y la protección de los derechos de los niños, vid., entre otros: G. van Bueren, The Internacional Law on the Rights of the Child, Dordrecht, Martinus Nijhoff, 1995, p. 6 ss. ; M. Calvo García, "La protección del menor y sus derechos" en Derechos y Libertades (1993) no 2, p. 177-99; I. Campoy Cervera, "Notas sobre la evolución en el reconocimiento y la protección internacional de los derechos de los Niños" en Derechos y Libertades n ${ }^{\circ} 6$ (1998), p. 279-327; J. Fortin, Children's Rights and the Developing Law, $2^{\text {a }}$ ed., Cambridge, CUP, 2005, p. 31 ss. reconocimiento en los planos regional y estatal ${ }^{7}$. Lo cual ha supuesto, sobre todo a partir de los desarrollos legislativos estatales, la judicialización de esferas importantes de protección y garantía de los derechos de la infancia y de la adolescencia; así como el desarrollo de instituciones nacionales específicas de protección de estos derechos. Por todo ello, las últimas décadas del siglo $\mathrm{XX}$ representan una inflexión importante en el discurso práctico de los derechos de la infancia y de la adolescencia.

Para empezar, los derechos reflejados en la Convención reflejan un orden social que podríamos llamar "ideal" desde el que se define la posición de los niños y de las niñas en la sociedad, así como el reparto de papeles entre los encargados de facilitar el ejercicio de sus derechos, fundamentalmente el Estado y la familia. Desde esta óptica, fácilmente podemos ver a la Convención como el logro de un largo y dilatado proceso que culmina con el pleno reconocimiento y efectividad de sus derechos tanto en el plano internacional como en el nacional.

\footnotetext{
${ }^{7}$ Para una pespectiva general sobre los derechos de la infancia en el plano europeo, puede verse G. Van Bueren, Child Rights in Europe. Convergence and divergence in Judicial Protection, Strasbourg, Council of Europe, 2007. Sobre el impacto de la Convención y las Observaciones Generales del Comité en las legislaciones e intervenciones de una muestra amplia de Estados, puede verse UNICEF-Centro de Investigaciones Innocenti, Las reformas legales y la implementación de la Convención sobre los derechos del niño, Florencia, Centro de Investigaciones Innocenti de UNICEF, 2008.
} 


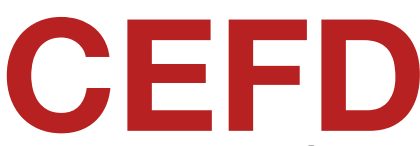

Cuadernos Electrónicos de Filosofía del Derecho

Ahora bien, es preciso darse cuenta de que la Convención expresa lo que en una determinada época (en la década de los 80 del siglo XX), los expertos y representantes de los diferentes Estados entendieron que había que asumir y reconocer expresamente con respecto a los derechos humanos de la infancia y de la adolescencia. En este sentido, la Convención era la vía que iba a permitir el máximo desarrollo de los derechos humanos por parte de los niños y las niñas. Así, en su preámbulo, la Convención se refiere a la Declaración Universal de los Derechos Humanos, recordando como ésta proclama que toda persona tiene todos los derechos y libertades enunciados en la misma, y a la vez, que la infancia tiene derecho a cuidados y asistencia especiales.

Con la Convención hemos asistido a un reconocimiento y especificación de los derechos de la infancia y de la adolescencia que los ha realzado y situado en la agenda de los organismos internacionales y estatales de protección de los derechos humanos. Es casi un tópico afirmar que la Convención sobre los derechos del niño es el texto del Derecho internacional de los derechos humanos que más ratificaciones tiene. Por otro lado, nuevos instrumentos han venido a reforzar las obligaciones que asumen los Estados y los mecanismos de supervisión y control de las mismas $^{8}$.

Concretamente la Convención partiendo de los derechos relativos a la protección, que ya estaban en la Declaración de los Derechos del Niño de 1959, añadió algunos otros referentes a su bienestar material, a garantizar el buen trato hacia los niños y a la participación. Todos ello en el contexto de los en ese momento Estados del bienestar, por un lado, y de acuerdo con las aportaciones de las ciencias sociales y con el mayor consenso que se preveía alcanzar entre los países para su aceptación y ratificación ${ }^{9}$. Con ello, la Convención vino a sancionar una determinada imagen de la infancia y la adolescencia para proponerla como forma universal de ser niño.

Este desarrollo por lo demás contempla estos derechos desde una perspectiva amplia, que incluye tres categorías de derechos. En primer

${ }^{8}$ Entre otros: el Protocolo facultativo de la Convención sobre los Derechos del Niño relativo a la venta de Niños, la Prostitución Infantil y la Utilización de Niños en la Pornografía, aprobado mediante resolución de 25 de mayo de 2000 (A/RES/54/263) y entrado en vigor con fecha de 18 de enero de 2002; el Protocolo facultativo de la Convención sobre los Derechos del Niño relativo a la Participación de Niños en los Conflictos Armados, aprobado mediante resolución de 25 de mayo de 2000 (A/RES/54/263) y entrada en vigor con fecha de 12 de febrero de 2006; y el Protocolo Facultativo de la Convención sobre los Derechos del Niño relativo a un procedimiento de Comunicaciones aprobado 19 de diciembre 2011 y que ha entrado en vigor en abril de 2014. Procedente de la OIT: el Convenio sobre la prohibición de las peores formas de trabajo infantil y la acción inmediata para su eliminación de 1999 (C 182), con fecha de entrada en vigor de 19 de noviembre de 2000, y la Recomendación R 190 vinculada al mismo.

9 Vid. L. Gaitán y M. Liebel, Ciudadanía y Derechos de Participación de los Niños, Madrid, Universidad Pontificia de Comillas-Editorial Síntesis, 2011, p. 30. 


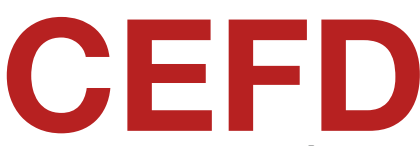

Cuadernos Electrónicos de Filosofía del Derecho

lugar, el "derecho a beneficiarse de algo", en el que se incluirían por ejemplo el derecho a ser alimentado, a ser cuidado, a recibir afecto, a tomar medicinas. En segundo lugar, el niño tiene "derecho a ser protegido de cualquier cosa", esto es, de aquello que atenta o puede atentar contra su integridad física o psíquica, ya sean malos tratos, tortura, explotación laboral, etc. ${ }^{10}$. Por último, estaría el derecho del niño a "hacer algo", a realizar alguna acción, como puede ser la de expresarse o participar en las decisiones que afecten a su vida ${ }^{11}$, lo que no es sinónimo de que todas sus decisiones hayan de ser respetadas sino más bien el derecho del niño a que sus opiniones $\mathrm{y}$ pareceres sean tenidos en la debida consideración $^{12}$. Del amplio reconocimiento que

\footnotetext{
${ }^{10}$ En este sentido señala C. Wellman, "el niño es más vulnerable que el adulto con respecto a ciertas clases de injusticia o daño (todas las formas de descuido, crueldad y explotación). Además el niño más que el adulto necesita tener unas oportunidades para desarrollarse física, mental, moral, espiritual y socialmente de una forma sana y normal", C. Wellman, An Approach to Rigths. Studies in the Philosophy of Law, Oxford, Oxford University Press, 1995, p. 132 ss.
}

${ }^{11}$ Experiencias concretas de este derecho a la participación de los niños/niñas en países latinoamericanos: vid. L.Wills Rivera, "La incorporación progresiva de los niños y niñas adolescentes a la ciudadanía activa"; J. M. Yac Huís, "Parlamento Guatemalteco para la niñez y adolescencia: garantizando la participación ciudadana justa", en C. Villagrasa Alcaide e I. Ravetllat Balleste (coords.), Por los derechos de la infancia y de la adolescencia. Un compromiso mundial desde el derecho de participación en el XX aniversario de la Convención sobre los Derechos del Niño, $1^{\mathrm{a}}$ ed., Barcelona, Bosch, 2009, p. 113-143 y 191-202 respectivamente.

\footnotetext{
${ }^{12}$ Sobre el derecho que tiene el niño a ser consultado y la tensión entre autonomía y paternalismo puede verse L. Hierro, "El niño y los derechos humanos", en I. Fanlo (comp.), Derechos de los niños. Una contribución teórica, $1^{\mathrm{a}}$ ed., México D.F., Fontamara, 2004, p. 177-197; y J. Fortin, Children's Rights and the Developing Law, $2^{\mathrm{a}}$ ed., Cambridge, CUP., 2005, p. 19 ss., 71 ss., 121 ss.
}

otorga la Convención de 1989 a los derechos del niño se empieza a dibujar el perfil de un menor y sobre todo de un adolescente árbitro de su propia vida, en condiciones de hacer valer sus propias elecciones y de ver garantizado su interés en las posibles confrontaciones con otros intereses.

Por otro lado, los principios recogidos en la Convención se fueron incorporando paulatinamente a las legislaciones internas de la práctica unanimidad de los países que han ratificado esta norma internacional como ley propia. En España este reconocimiento tuvo lugar en virtud de la Ley Orgánica 1/1996, de 15 de enero, de Protección Jurídica del Menor y de la legislación de las Comunidades Autonómas. Estas reformas legales expresaron y trataron de plasmar en el derecho español unos principios radicalmente distintos a los existentes en ese momento sobre las personas menores de edad ${ }^{13}$.

Recientemente se ha aprobado en España una modificación normativa al sistema de protección a la infancia y adolescencia: Ley Orgánica 8/2015, de 22 de julio, y Ley 26/2015, de 28 de julio, que afectan entre otras a la referida L.O. 1/1996, de

\footnotetext{
13 Ya antes en el marco de los trabajos preparatorios de la Convención sobre los Derechos del Niño, la Ley española 21/1987 de acogimiento y adopción se hacía eco del principio del superior interés del menor que había de guiar todas las actuaciones en materia de protección de la infancia (guarda administrativa, tutela administrativa, acogimiento y adopción). Ley que sin duda supuso una auténtica "revolución" en el derecho civil español con medidas de protección como la "tutela administrativa ope legis" (que desde la L.O 1/1996 tiene como efecto la suspensión de la patria potestad).
} 
Cuadernos Electrónicos de Filosofía del Derecho

Protección Jurídica del Menor y también a la L.O. 1/2004, de 28 de diciembre, de Medidas de Protección Integral contra la Violencia de Género. Concretamente, la referida Ley Orgánica 8/2015, de 22 de julio de modificación del sistema de protección de la infancia y la adolescencia y la Ley 4/2015, de 27 de abril, del Estatuto de la Víctima, reconocen a los y las menores como víctimas de la violencia de género. El reconocimiento de los niños y niñas como víctimas directas e indirectas de la violencia de género en el ámbito de la relación de pareja tiene una relevancia singular, por lo que le dedicaré unas breves reflexiones al final del artículo.

En definitiva, la Convención sobre los Derechos del Niño sigue siendo en la actualidad el texto normativo internacional más importante en ofrecer un tratamiento global de la infancia. En este sentido, su aprobación por la Asamblea General de las Naciones Unidas supuso una inflexión en los derechos de la infancia y de la adolescencia, al introducir un cambio de paradigma, ya que progresivamente se fue dejando de considerar a las personas menores de edad como seres únicamente merecedores de protección jurídica por parte de los adultos y de los poderes públicos, para pasar a considerarlos como sujetos de derecho ${ }^{14}$. Sin menoscabo, por

${ }^{14}$ Vid. C. Villagrasa, "Derechos de la Infancia y Adolescencia: Hacia un sistema legal", en Anales de la Cátedra Francisco Suárez otro lado, de la atención que requieren aquellos menores que por las circunstancias irregulares de su entorno precisan de una respuesta jurídica protectora por encontrarse en una situación de "riesgo" o de desamparo".

Ahora bien, este modelo de los derechos del niño recogido en la Convención no deja de suscitar polémicas e incluso puede y debe ser objeto de escrutinio desde una perspectiva crítica. Más de veinticinco años después de su aprobación ha llegado el momento de hacer un balance crítico de la Convención sobre los Derechos del Niño. De entrada resulta ineludible, como se ha señalado al comienzo de este artículo, plantear críticamente el discurso de los derechos del niño tal y como cristalizó en la Convención.

En el apartado siguiente se va analizar qué concepción o concepciones de la infancia han quedado recogidas y qué otras concepciones de la infancia han quedado en los margénes de la Convención por motivos culturales, sociales, antropológicos, etc. En este sentido, el "género" podría abordarse conjuntamente con los demás motivos o condiciones, pero para poder profundizar mejor en el tema lo abordaré después en un apartado independiente.

(2015) $\mathrm{n}^{\circ}$ 49, p. 18. Vid. también: I. Ravetllat Ballesté, Aproximación histórica a la construcción sociojurídica de la categoría infancia, cit., p. 63-64. 


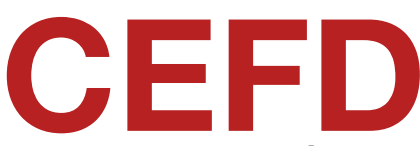

Cuadernos Electrónicos de Filosofía del Derecho

\section{El concepto de infancia en la Convención y la diversidad cultural y social: Otras infancias}

En el marco de la Convención sobre los Derechos del Niño y de las legislaciones nacionales que fueron apareciendo después, el principal esfuerzo internacional en torno a los derechos de la infancia ha estado focalizado en encontrar cómo garantizar que niños y niñas tengan y puedan disfrutar de sus derechos. En este sentido, se ha considerado a la Convención -y a todo el desarrollo legal y legislativo a que ha dado lugarcomo punto culminante. De forma que se ha entendido que sólo quedaba pendiente lograr la implementación de los derechos reconocidos formalmente.

Sin embargo, al concentrar todos nuestros esfuerzos teóricos y prácticos en ello estabámos dejando de lado otras realidades sociales $\mathrm{y}$ culturales en las que se desenvuelven "otras infancias" que quedaron en los márgenes de la Convención. Precisamente, nos interesa reparar en este apartado en cómo y por qué esas "otras infancias" se quedaron en los márgenes. Lo que nos lleva a la necesidad de revisar el modelo de derechos del niño tal y como quedó recogido en la Convención. Sin dejar de dar valor a la interesante evolución que, a lo largo de los años, ha habido en la interpretación tanto de los derechos como del principio rector del superior interés del niño ${ }^{15}$.

De entrada hay que señalar que el artículo 2 de la Convención recoge el principio de igualdad, uno de los llamados principios rectores por el Comité de los Derechos del Niño. El cual se formula desde el prisma de la no discriminación. En este sentido, el artículo 2 de la Convención señala que los derechos en ésta reconocidos se disfrutarán sin distinción alguna por motivo de raza, color, sexo, origen nacional o social, etc. Pero esta consideración y otras en las que la Convención se hace eco de las diferencias y diversidades culturales y/o sociales de la infancia, son a todas luces insuficientes no sólo para la eficacia sino también para el reconocimiento y garantía de los derechos de los niños y las niñas. Y ello porque, entre otras razones, la Convención sobre los Derechos del Niño; así como la práctica de sus derechos, se basan en una concepción homogénea de la infancia y por ello "minoritaria"16.

${ }^{15}$ En el caso español, el legislador en la nueva redacción del artículo 2 de la L.O. de Protección Jurídica del Menor, modificada por la L.O. 8/2015, de 22 de julio, define el principio rector del interés superior del niño desde una triple perspectiva, a saber: como un derecho sustantivo, como un principio general de carácter interpretativo y como una norma de procedimiento. Según I. Ravetllat Ballesté, esta reforma "vigoriza el interés superior del niño (...) frente a la limitada configuración de la antigua redacción del art. 2 que tan sólo lo contemplaba desde su vertiente de principio general inspirador (...). Al proclamar además su carácter de derecho sustantivo y su carácter de norma de procedimiento"; vid. I. Ravetllat Ballesté, "El interés superior del niño a la luza del nuevo artículo 2 de la Ley Orgánica 1/1996, de 15 de enero", en laleydigital 360, versión electrónica: http://laleydigital.laley.es/.

${ }^{16}$ Vid. M. Cordero Arce, "Towards an Emancipatory Discourse of Children Rights" en International Journal of Children's Rights 
Cuadernos Electrónicos de Filosofía del Derecho

En su Observación General número 14 UNCRC, 2013 (publicada el 29 de mayo de 2013) ${ }^{17}$, el Comité de los Derechos del Niño señala que es necesario tener presente que los niños no son un grupo homogéneo (55 §). Según el Comité, para determinar el interés superior del niño se han de tomar en consideración las circunstancias específicas de cada caso asegurando que éstas incluyan las características individuales de los niños o del grupo de los niños como "edad", "género", "grado de madurez", "experiencia", "pertenencia a grupos minoritarios", etc. Igualmente se ha de considerar el contexto social y cultural en el que viva el niño, la presencia o ausencia de padres, el hecho de que el niño o niña viva o no con ellos, la calidad de las relaciones y los vínculos que tenga con su familia o las personas que están a su cargo, etc. (48 §). Por tanto, desde la perspectiva de la identidad del niño o niña habrá que reparar en su diversidad para poder determinar cuál es su superior intéres. Más concretamente, la identidad implica aspectos como género, orientación sexual, origen nacional, religión y cosmovisión, identidad cultural y

(2012) 20, p. 369 .

17 Observación General $n^{o} 14$ del Comité de los Derechos del Niño, del 29 de mayo de 2013, sobre el derecho del niño a que su intéres superior sea una consideración general. personalidad $^{18}$. En este sentido, el Comité estima que si bien existen necesidades universales que son comunes a todos los niños y niñas; la expresión de estas necesidades depende de toda una serie de aspectos personales, físicos, sociales y culturales (55 §).

Por otro lado, el Comité subraya además que el interés superior debe concebirse tanto como un derecho individual como colectivo (23 §). En este sentido, M. Liebel considera que el principio del interés superior se refiere también a intereses colectivos y grupales $^{19}$. Concretamente el Comité pone como ejemplo la realidad de los niños indígenas, cuyo superior interés está relacionado con los derechos culturales de las minorías indígenas.

En definitiva, el Comité se esfuerza en ofrecer pautas para poder interpretar el principio rector del interés superior del niño o niña, además de recoger algunos ejemplos de la situación específica de niñas y niños a nivel local. Otro aspecto que no debemos subestimar es el hecho de que el Comité declara como sujetos de derechos explícitamente a grupos de niños, mientras que la Convención no lo hace con la misma claridad. De manera general, el

\footnotetext{
${ }^{18}$ Vid. M. Liebel, "Sobre el interés superior de los niños y la evolución de sus facultades", en Anales de la Cátedra Francisco Suárez (2015) no 49, p. 48.

${ }^{19}$ Ibídem, p. 47 y 49.
} 
Cuadernos Electrónicos de Filosofía del Derecho

Comité deduce los intereses del niño de los derechos establecidos en la Convención y los identifica con ellos. Al relacionarlo con los contextos sociales y culturales, lo que hace es objetivizarlos en alguna medida. Hecho que significa un gran desafío para el análisis de los intereses del niño y su consideración de la realidad social ${ }^{20}$.

Desde la perspectiva de la sociología de la infancia se pueden distinguir diversas concepciones de infancia, las cuales van intrínsecamente unidades a otras realidades culturales y otras variables como las de la etnicidad, clase y género. En este sentido, para estas corrientes críticas, la definición legal y singular de "niño" es un instrumento muy limitado que deja fuera esas otras formas de ser niño o niña en el mundo y con ello, dificulta que las respuestas del derecho se adapten a la diversa realidad en la que viven muchos niños y niñas. Por lo que no debería extrañarnos que, en definitiva, los estándares de los derechos de los niños se vean continuamente saboteados. Así, B. Mayall $^{21}$ considera que si trabajamos hacia una mejor comprensión de la condición social de la infancia, de las diversas infancias, podremos

\footnotetext{
${ }^{20}$ Ibídem, p. 49.

${ }^{21}$ Vid. B. Mayall, "The sociology of childhood in relation to children's rights", en The International Journal of Children's Rights (2000) 8, p. 243.
}

sentar unas bases firmes para la implementación de sus derechos.

Por tanto, es preciso y urgente darse cuenta de que las diversas concepciones de la infancia a las que pertenecen los niños y las niñas son sin duda determinantes para la eficacia de sus derechos. Y ello porque, entre otras cosas, los conceptos culturales dominantes en la formulación de los derechos humanos en general y de los derechos de los niños y niñas, en particular, dificultan la mirada y la recepción de las particularidades de las diferentes culturas y comunidades.

Para L. Gaitán y M. Liebel ${ }^{22}$, resulta indudable que los mecanismos en los que se articulan y los principios y valores en los que se basan los derechos humanos en general $\mathrm{y}$, los derechos de los niños y niñas en particular, acaban siendo útiles sólo a aquellas personas que están en una posición desde la cual pueden considerararlos como relevantes para sí mismos. Por ello, no basta con reconocer los derechos de los niños y aplicarlos sino que es preciso "traducirlos" para que puedan ser compatibles con las tradiciones, las prácticas locales y con las diversas experiencias de infancia que viven otros muchos niños y niñas. Y ello exige tener en consideración además de sus derechos todo el conjunto de interrelaciones y obligaciones mutuas que viven

\footnotetext{
22 Vid. L. Gaitán y M. Liebel, Ciudadanía y derechos de participación de los niños, cit., 2011, p. 56.
} 
Cuadernos Electrónicos de Filosofía del Derecho

los niños y niñas, no sólo entre ellos sino también con los adultos.

Tal y como hemos señalado al principio de este apartado, en el marco de la Convención sobre los Derechos del niño y de las legislaciones nacionales que aparecieron después, el principal esfuerzo internacional en torno a los derechos del niño ha ido dirigido fundamentalmente a garantizar que niños y niñas tengan y puedan disfrutar de sus derechos. Sin querer restar importancia a tan relevante cuestión, no podemos dejar de subrayar el descuido $\mathrm{u}$ olvido de esas otras realidades sociales, culturales en medio de las cuales se desenvuelven esas otras infancias que quedaron en los márgenes de la Convención, que no encajan en esa concepción homogénea de la infancia, tal y como quedó allí recogida.

No sólo estamos pensando en los niños y niñas que viven en las calles o que se ven obligados por unas razones o por otras a participar en los conflictos bélicos, entre otras problemáticas. En Europa, por ejemplo, los niños y niñas que han escapado de sus países de origen sin el acompañamiento de un familiar, sin duda constituyen esas otras infancias que han quedado fuera de ese concepto homogéneo y minoritario de la infancia característico de la Convención.
En particular, los procesos migratorios han generado que entre los menores en situación de desprotección de nuestras sociedades exista un grupo con características y necesidades específicas, como es el colectivo de los menores inmigrantes no acompañados ${ }^{23}$. En general, se trata de adolescentes indocumentados que han dejado a su familia en su lugar de origen y que por su condición de menores de edad deben ser protegidos por las instituciones y la sociedad que los recibe. Más específicamente, la infancia y adolescencia vinculada a la inmigración presenta una doble cara. Por un lado, las migraciones tienen una cara amable por el enriquecimiento que ofrece la mezcla de conocimientos, costumbres, culturas. Pero lamentablemente, por otro lado, está la cara amarga de una infancia mal protegida tras el retraso económico del país de origen y que continúa siéndolo tras la emigración a los países de acogida a causa de la creciente exclusión social y cultural. El riesgo reside desde luego en la desprotección que pueden padecer bajo dos marcos sociales y normativos (el de origen y el de destino de las migraciones), en medio de los cuales se esconde la desigualdad de oportunidades, las diferencias por motivos

${ }^{23}$ Una interesante y completa definición de la realidad de los menores extranjeros no acompañados se puede consultar en: G. Mosconi, "Prefazione", en A. Sbraccia e Ch. Scivoletto (eds.), Minori Migranti: Diritti e Devianza. Ricerche Socio-Giuridique sui minori non accompagnati, Torino, L'Harmattan Italia, 2004, p. 5 


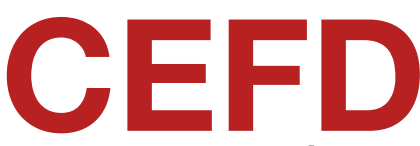

Cuadernos Electrónicos de Filosofía del Derecho

culturales o la discriminación por origen nacional $^{24}$.

Es preciso además concienciarse de como pueden producirse algunos efectos perversos en el contexto de los Estados democráticos de bienestar, cuyas políticas de protección de los derechos de los niños se articulan fundamentalmente en el marco de una concepción cultural homogénea de la infancia. Y ello, entre otras razones, porque el indicador legal de que un niño o niña "esté solo o abandonado" se basa en considerar que la auténtica infancia se relaciona con la vida familiar, doméstica, en la que niños y niñas son cuidados por los adultos ${ }^{25}$. Desde esta óptica, los menores no acompañados, solos, sin adultos, son existencias anormales y "en peligro o peligrosas" de las que de entrada hay que desconfiar y "socializar" y/o "educar de una determinada manera". Olvidando con ello que

${ }^{24}$ Vid. M.J. Pérez Crespo y V. Hernández Solís, "Territorio globalizado: ¿realidad o ficción vista desde la infancia en la inmigración?, en M. Calvo García y J. Guilló Jiménez (coords.), Globalización y derechos de la infancia y la adolescencia, Zaragoza, LSJUZ_Centro de Investigación y Documentación de la Infancia y Adolescencia, 2007, p. 37-58. Sobre la problemática que presentan estos menores pueden verse, entre otros, los siguientes estudios: Informe extraordinario de la Institución del Ararteko al Parlamento Vasco, Situación de los menores extranjeros no acompañados en la CAPV, Ararteko, 2005, p. 69112; J. R. Bueno Abad y F. J. Mestre Luján, "La protección de menores no acompañados", en Revista Alternativas. Cuadernos de Trabajo Social (2006) n ${ }^{\circ} 14$ p. 159-170; A. Sbraccia e Ch. Scivoletto (eds.), Minori Migranti: Diritti e Devianza. Ricerche Socio-Giuridique sui minori non accompagnati, Torino, L'Harmattan Italia, 2004.

${ }^{25}$ Vid. M. Cordero Arce, Hacia un discurso emancipador de los derechos de las niñas y los niños, Lima, IFEJANT, 2015, p. 235237. estos menores son justamente esas otras infancias que viven al margen de la concepción dominante de infancia, desconectados de sus familias y que posiblemente viven bajo su propia responsabilidad y ocupándose de sí $\operatorname{mismos}^{26}$. El resultado es que todos estos niños y niñas quedan a merced de las decisiones normalmente basadas en "su mejor interés" por parte de los organismos y administraciones. Lo que, en la mayor parte de los casos, se traduce en que acaban siendo alojados en centros y establecimientos no adecuados para ellos; otras veces detenidos o internados en centros cerrados con unas muy rígidas normas de entrada y salida. Muchas veces tampoco logran un acceso a una educación o a una formación profesional adecuada para ellos, etc. En este sentido, la educación se articula mucho más sobre unas bases psicológicas que sociológicas, y son más objeto de socialización ${ }^{27}$. Así, sus puntos de vista no se valoran, mientras que su futuro depende de decisiones "que se extienden" a lo largo de arduos y complicados procedimientos y procesos, de los que tienen poca información y que sin embargo son esenciales para sus expectativas de quedarse o no en el país de acogida.

\footnotetext{
26 Vid. L. Gaitán y M. Liebel, Ciudadanía y derechos de participación de los niños, cit., p. 58.

27 Vid. B. Mayall, "The sociology of childhood in relation to children's rights", cit., p. 246.
} 


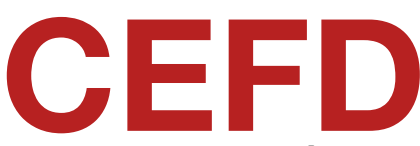

Cuadernos Electrónicos de Filosofía del Derecho

Críticamente algunos investigadores consideran que la Convención está articulada en el marco de los conceptos occidentales (western concepts). Concretamente, la Convención hace referencia a la infancia "universal", "free-standing" e individualizada; esto es, al niño que se encuentra en una determinada etapa de su desarrollo. Lo que implica que las relaciones biológicas basadas en el vínculo padres-hijos son más relevantes $\mathrm{y}$ naturales que otras clases de relaciones familiares o de comunidad ${ }^{28}$. De ahí que, la concepción de "infancia" y el discurso de los derechos del niño dominante en la Convención tiene mucho que ver, en palabras de M. Cordero Arce, con la realidad de una infancia "europea y americana" e “individual". Por lo que inevitablemente se sitúa en los margénes o fuera de la misma cualquier otra concepción de infancia o infancias ${ }^{29}$.

Por otra parte y desde una perspectiva totalmente distinta como es la de una ética de los derechos, algunas autoras consideraban políticamente cuestionable la positivización que había hecho la Convención sobre los Derechos del Niño en los años finales de los 80 y 90 del siglo $\mathrm{XX}^{30}$. No es

\footnotetext{
${ }^{28}$ Ibídem, p. 245.

${ }^{29}$ Vid. M. Cordero Arce, "Towards an Emancipatory Discourse of Children Rights", cit., p. 383; vid. también: J. L. Fernando, "Children's Rights: Beyond the impasse" en The Annals of the American Academy of Political and Social Science (2001) 575, p. 8-24.

${ }^{30}$ M. Minow, "Rights for the next generation: A feminist approach to children's rights" en Harvard Women's Law Journal (1986) vol
}

que se opusieran al hecho de legalizar los derechos de los niños. Simplemente consideraban que la Convención estaba pasando por alto una concepción ética de los derechos, ya que desde el momento en que se negaba la existencia de cualquier obligación se estaban disminuyendo los correspondientes derechos.

Concretamente, para M. Minow la noción de “obligación” podría enriquecer la discusión sobre los derechos de los niños, pues, el concepto de obligación introduce una dimensión bilateral que da contenido a los derechos ${ }^{31}$. Así, al formular obligaciones se prestaría más atención a los aspectos de los derechos "comprometidos", a facilitar las relaciones y vínculos personales. De este modo, expresarían un compromiso social con la libertad individual para construir relaciones con los otros. Según Minow, el objetivo de la autonomía $^{32}$ no debería ser abandonado sino que

9, p. 23 ss.; O. O’Neill, “Children's Rights and Children's Lives”, en Ph. Alston, S. Parker, J. Seymour (eds.), Children Rights and the Law, Oxford, Oxford Clarendon Press, 1992, p. 24-25.

${ }^{31}$ Vid. M. Minow, "Rights for the next generation: A feminist approach to children's rights", cit., p. 23-24.

${ }^{32}$ No se va a profundizar en este trabajo en la interesante polémica entre "paternalismo" y "derechos de los niños". De la cual, en un momento anterior y con mayor profundidad se han ocupado, entre otros: N. MacCormick, "Los derechos de los niños: una prueba para las teorías del derecho", en Derecho Legal y Socialdemocracia. Ensayos sobre filosofía jurídica y política, trad. M. Lola González Soler, Madrid, Tecnos, 1982, p. 129-137; E. Garzón Valdés, “ 'Desde la modesta propuesta” de J. Swift hasta las casas de engorde'. Algunas consideraciones acerca de los derechos de los niños", en Doxa (1994) no 15-16, p. 731-737; I. Campoy Cervera, La fundamentación de los derechos de los niños. Modelos de reconocimiento y protección, cit., p. 440-477; M. D.A. Freeman, "Taking Children's Rights More Seriously", en $\mathrm{Ph}$. Alston, S. Parker, J. Seymour (eds.), Children Rights and the Law, Oxford, Oxford Clarendon Press, 1992, p. 52-71; J. Eekelaar, "The 
CEF

Cuadernos Electrónicos de Filosofía del Derecho

tendría que articularse con el objetivo de la asociación con otros.

Según estas reflexiones críticas, podría decirse que la Convención ilustra más ampliamente acerca de los problemas o dificultades a que da lugar cualquier proyecto o ley que se propone mejorar la vida de un determinado grupo de personas concediéndoles derechos. Y ello porque las leyes que conceden derechos contienen tensiones, ambiguedades y conflictos. En el caso de los derechos de los niños y niñas estas tensiones y gaps son todavía más pronunciadas. A menudo se darán conflictos entre los derechos de los niños y los de sus progenitores (reforzados por los Estados); y entre sus derechos y los del Estado (protegidos a través del empoderamiento a los padres). El conflicto ya clásico entre la igualdad sustancial y la igualdad formal toma la forma del conflicto entre el derecho de los niños a ser protegidos y el derecho de los niños a ser tratados

importance of thinking that chidlren have rights", en $\mathrm{Ph}$. Alston, S. Parker, J. Seymour (eds.), Children Rights and the Law, Oxford, Oxford Clarendon Press, 1992, p. 221-235; ID., "The Interests of the Child and the Child's Wishes: The Role of Dynamic SelfDeterminism", en International Journal of Family Law (1994) $\mathrm{n}^{\circ}$ 8, p. 42-61; T.D. Campbell, "The Right of the Minor: as Person, as Child, as Juvenil, as Future Adult", en Ph. Alston, S. Parker, J. Seymour (eds.), Children Rights and the Law, Oxford, Oxford Clarendon Press, 1992, p. 1-23; O. O'Neill, “Children's Rights and Children's Lives”, en Ph. Alston, S. Parker, J. Seymour (eds.), Children Rights and the Law, Oxford, Oxford Clarendon Press, 1992, p. 24-42 (de algunos de estos últimos trabajos hay traducción al castellano: en I. Fanlo (comp.), Derecho de los niños. Una contribución teórica, $1^{\mathrm{a}}$ ed., México D.F., Fontamara, 2004 (p. 77-106, 107-141 y143-175 respectivamente). como los demás ${ }^{33}$-lo que significa a ser tratados como un adulto-. Y si a ello añadimos el derecho de niños y niñas a promover sus habilidades para construir relaciones de confianza, significado y afectivas con otras personas en su vida diaria y en sus comunidades, estos conflictos se multiplican o al menos las tensiones a las que da lugar ${ }^{34}$.

Cabría preguntarse si el interés superior del niño se entiende únicamente en el sentido del bienestar del niño o si implica además que los niños y niñas tienen derecho a participar en las decisiones sobre su vida ${ }^{35}$. En este sentido, señala M. Liebel que no basta con identificar a los niños y niñas como sujetos de derecho a un nivel meramente formal sino que además y de forma concreta debemos ver a los niños y niñas como sujetos sociales. Lo que tiene que ver, con el significado práctico que los

${ }^{33}$ Así, el art. 12 de la Convención garantiza a los niños poder expresar su opinión libremente en todos los asuntos que les afecten y que, en el momento de tomar decisiones, sus opiniones serán debidamente tomadas en cuenta. Si bien el mismo artículo condiciona el ejercicio de este derecho al decir "que el niño esté en condiciones de formarse un juicio propio" y que se tomará en consideración su opinión "en función de su edad y grado de madurez". De lo que se deriva que el niño debe tener la oportunidad de expresarse y ser oído en todos los procedimientos judiciales o administrativos que le conciernan (art. 12. 2); y especialmente, en aquéllos en los que se esté decidiendo una posible separación del niño con respecto a su padres, en los que participará y expresará sus apreciaciones directamente o a través de un representante (art. 9.2). Y la protección de su libertad se extiende a los concretos ámbitos del pensamiento, conciencia, religión y asociación; así como la tutela abarca su vida privada, su familia, su domicilio y su correspondencia --esfera, ésta última, que no podrá ser objeto de injerencias arbitrarias o ilegales (arts. $13,14,15$ y 16$)$.

${ }^{34}$ Vid., F. Olsen, “Children's Rights: Some feminist approaches to the United Convention on the Rights of the Child", en International Journal of Law and the Family (1992) 6, p. 213.

35 Vid. M. Liebel, "Sobre el interés superior de los niños y la evolución de sus facultades”, cit., p. 44. 


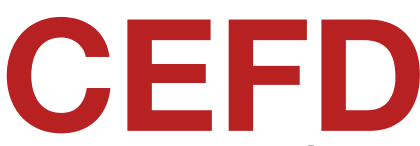

Cuadernos Electrónicos de Filosofía del Derecho

derechos pueden adquirir para la defensa de sus intereses, de forma que sus derechos tengan sentido para los niños y niñas en su vida cotidiana.

En definitiva, el tema del interés superior del niño no sólo surge cuando se habla del desarrollo de la vida del niño o del aspecto generacional sino también en vista de las diferencias entre los niños mismos. En la realidad, las diferencias entre niños menores y mayores, entre niños y niñas, entre niños de diferente origen social, situación de vida $\mathrm{u}$ origen étnico son grandes. Para M. Liebel este tipo de diferencias en algunos supuestos pueden incluso resultar más importantes que las que existen entre niños y adultos. Por otro lado, estas diferencias no se refieren únicamente a las competencias y posibilidades de acción que se les concedan a los niños, sino que van referidas también a la posición en la que ellos mismos se ven dentro de su comunidad o sociedad ${ }^{36}$.

Lo cierto es que estas diferencias no son sólo cronológicas, ni sólo tienen que ver con las

\footnotetext{
${ }^{36}$ Lo cual en definitiva supone que estamos hablando de una extensa y diversa gama de formas de expresión, potenciales de acción y posibilidades de tomar decisiones sobre su propia vida. Cuestiones todas ellas que nos conducen a la interesante y debatida cuestión de la participación y de la autonomía de los niños y niñas, de las que por razones obvias no me puedo ocupar en este trabajo. Vid. T. Picontó Novales, En las fronteras del derecho. Estudio de casos y reflexiones generales, Madrid, Dykinson, 2000, p. 31-38; ID., "Religious Freedom and Protection of the Right to Life in Minors: A Case Study", en M. Maclean and J. Eekelaar (ed.), Managing Family Justice in Diverse Societies, Hart Publishing/Oñati International Institute for The Sociology of Law, 2013, p. 137-151
}

características mentales o físicas. Sino que están directamente relacionadas con las experiencias de vida de cada niño y niña ${ }^{37}$. Y por ello también depende de las oportunidades que se brinden a cada uno de ellos para que puedan desarrollar las capacidades relevantes para su autocomprensión y acción. En este sentido, el derecho de los niños y niñas a la participación es considerado un derecho fundamental de la ciudadanía y podrá ejercirtarlo sólo a través de la oportunidad de formar parte del proceso de toma de decisiones en la familia, en la escuela y en la comunidad local ${ }^{38}$. Del mismo modo, en su calidad de sujetos sociales, niñas y niños pueden influir en las condiciones sociales que son relevantes para su desarrollo, reconocimiento y uso de sus capacidades. Claro que esto no es posible para todos los niños y niñas en la misma medida o sin restricciones. Cuestión que, como se ha señalado anteriormente (vid. supra nota 36$)$, no se va a abordar en este trabajo.

En definitiva, precisamos de una mejor comprensión de la infancia que nos permita darnos cuenta de aquellas características de la infancia a las que no se les prestó una suficiente atención en la redacción de la Convención sobre

\footnotetext{
${ }^{37}$ Vid. M. Liebel, "Sobre el interés superior de los niños y la evolución de sus facultades", cit., p. 57.

${ }^{38}$ Vid. R. Bosisio, "Children's Rights to be Heard: What Children Think", International Journal of Children's Rights (2012) 20, p. 143-144; M. J. Bernuz, "El derecho a ser escuchado: el caso de la infancia en conflicto con la norma", en Derechos y Libertades (2015) $\mathrm{n}^{\circ}$ 33, p. 74; M. Cordero Arce, Hacia un discurso emancipador de los derechos de las niñas y de los niños, cit., p. 210-211
} 
CEFD

Cuadernos Electrónicos de Filosofía del Derecho

los Derechos del Niño ${ }^{39}$. Con estas bases podremos re-pensar la infancia y subsanar aquellas carencias y limitaciones que presenta la Convención en aras de una mejora de los derechos de todos los niños y niñas. En definitiva, no basta con aplicar o implementar los derechos del niño sino que es necesario "traducirlos", esto es, hacerlos compatibles con las realidades, visiones y prácticas de manera contextualizada, teniendo en cuenta cada situación particular de niños y niñas.

En relación con ello hay que tener en cuenta, además, las desigualdades que se dan entre los diferentes grupos de niñas y niños ${ }^{40}$. Desigualdades que, por otra parte, se deben a razones estructurales $\mathrm{y}$, por tanto, las consecuencias en el acceso a sus derechos pueden ser grandes. Y dado el gran calado de estas desigualdades no se puede cerrar este trabajo sin analizar alguna de ella, de la que me voy a ocupar en el apartado siguiente y último de este artículo.

\section{Los derechos de la infancia en clave de} género

\footnotetext{
39 Vid. B. Mayall, "The sociology of childhood in relation to children's rights", cit., p. 252-253.

${ }^{40}$ Vid. M. Liebel, "Sobre el interés superior de los niños y la evolución de sus facultades", cit., p. 58.
}

Como se ha señalado al principio de este artículo resulta ineludible incorporar una decidida perspectiva de género en el discurso de los derechos de los niños a la vista de la realidad social, económica y cultural diferenciada y muchas veces discriminatoria para las niñas en ámbitos como, entre otros, el familiar, sanitario, educativo, justicia juvenil o laboral. En este sentido coincido plenamente con A. Rubio cuando dice que es imprescidible aludir de forma expresa a los derechos de las niñas al hablar de la Convención o, en general, cuando se analiza y estudia los derechos de la infancia $y$ adolescencia $^{41}$.

Concretamente, la especificidad de la discriminación que sufren las niñas es consecuencia, por un lado, de su pertenencia al grupo social de los menores de edad y, por otro, de su pertenencia al grupo social de las mujeres. Según A. Rubio la discriminación contra las niñas se construye a través del modelo antropológico "sujeto-ciudadano" 42 . Concretamente, en muchos contextos sociales y culturales las niñas pueden verse sometidas a una mayor discriminación porque no son percibidas como potenciales sujetos-ciudadanos.

\footnotetext{
${ }^{41}$ Vid. A. Rubio, "La igualdad de género: Los derechos de las niñas", en Ruth Mestre Mestre (coord.), Mujeres, derechos y ciudadanía, Valencia, Tirant lo Blanch, p. 245.

${ }^{42}$ Ibídem, p. 259.
} 


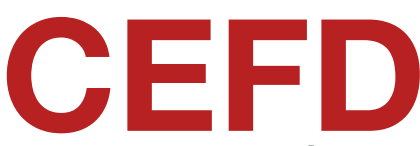

Cuadernos Electrónicos de Filosofía del Derecho

En términos generales, puede afirmarse que muchas de las circunstancias que afectan a las mujeres inciden de manera especial sobre las niñas como la feminización de la pobreza, por ejemplo $^{43}$. De forma que las niñas son víctimas de una doble discriminación: por edad y por género. La causa última de la discriminación que sufren las niñas es estructural, si bien los efectos de la discriminación sobre las niñas son individuales.

Es significativo que durante los trabajos preparatorios de la Convención sobre los Derechos del Niño una de las preocupaciones de los estudios feministas y de género fue la de determinar hasta qué punto la protección de los intereses y derechos de la infancia podría a la larga servir para controlar o constreñir más a las mujeres $^{44}$. Estos mismos estudios denunciaban

\footnotetext{
${ }^{43}$ Concretamente, la feminización de la pobreza afecta de forma especial a las niñas. En este contexto de "pobreza de recursos económicos" el Relator Especial del Derecho a la Alimentación en su Informe de 1999 (Informe sobre la realización del derecho a la alimentación y el derecho a permanecer libre de hambre) subrayaba la importancia de prestar atención, entre otros factores, "al papel que juega la malnutrición de mujeres y niñas en la transmisión intergeneracional de la malnutrición y en algunos procesos relacionados como, entre otros, el sistema inmunitario débil y el riesgo de muerte durante la lactancia, etc". Otro documento importante, del 24 de diciembre de 2012, es el Informe presentado al Consejo de Derechos Humanos por el Relator Especial sobre el derecho a la alimentación (Oliver De Schutter). Este informe concluye con la recomendación de que los Estados tengan en cuenta las necesidades y prioridades de las mujeres y las niñas en sus estrategias de seguridad alimentaria, y al mismo tiempo tengan en cuenta las limitaciones específicas que sufren las mujeres y transformen la división de funciones existente, basada en el género.

${ }^{44}$ Vid. F. Olsen, “Children's Rights: Some feminist approaches to the United Convention on the Rights of the Child", cit., p. 194195.
}

que la Convención había omitido referirse a problemáticas que afectan muy especial $\mathrm{y}$ negativamente a las niñas, como la de los matrimonios de las menores. En este mismo sentido, algunos de estos estudios feministas se preguntaban hasta qué punto la Convención podría estar reforzando una "ética del cuidado" antes que una "ética de los derechos",45. En definitiva, una de las cuestiones iniciales que se planteó críticamente a la Convención tuvo que ver con la preocupación de cómo iba a afectar este instrumento a la lucha por los derechos y el empoderamiento de las mujeres en general y también en el ámbito de la familia.

Desde una perspectiva social, se aprecia como las relaciones familiares y de parentesco condicionan el contexto particular en el que las niñas viven, se desarrollan; además de que influyen significativamente en lo que son $\mathrm{y}$ en lo que serán, condicionando no sólo su presente sino también su futuro ${ }^{46}$. Para M. Lagarde desde el nacimiento y aún antes las mujeres forman parte de una historia que las conforma como madres y

\footnotetext{
${ }^{45}$ Vid. F. Olsen, “Children's Rights: Some feminist approaches to the United Convention on the Rights of the Child", cit., p. 208 ; M. Minow, "Rights for the next generation: A feminist approach to children's rights" en Harvard Women's Law Journal (1986) 9, p. 17-18; ID., "Children's Rights. Where we've been, and where we're going", en Temple Law Review (1995) 68, p. 1581, 1583; B. Mayall, "The sociology of childhood in relation to children's rights", cit., p. 250-251.

${ }^{46}$ Vid. B. Leyra Fatou, Las niñas trabajadoras. El caso de México, Madrid, La Catarata, 2012, p. 105.
} 


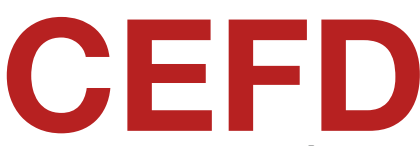

Cuadernos Electrónicos de Filosofía del Derecho

$\operatorname{esposas}^{47}$. La maternidad y la conyugalidad son las esferas vitales que organizan y conforman los modos de vida femeninos y ello, sin duda, con independencia de la edad, de la clase social y de otras variables.

Por otro lado, según S. Valente, los altos indices de matrimonio infantil en el Sur de Asia (50\%) y en África Central, Occidental y Subsahariana (cerca del 40\%) tienen a su vez un gran impacto en la malnutrición de mujeres, niños y niñas, siendo mucho más severa en el sur de Asia, donde el estatus social de la mujer es todavía más bajo ${ }^{48}$. Concretamente, considera que el hambre y la malnutrición siguen existiendo porque la mujer continúa siendo tratada como una ciudadana de segunda clase en la mayor parte del mundo, con un control limitado sobre su propia vida y sobre sus derechos sexuales y reproductivos, con un acceso limitado a la tierra, a la educación y al empleo con sueldo equitativo, muchas veces sujeta a la violencia en casa y en la sociedad. De ahí que una completa promoción de los derechos de las niñas y de las mujeres sea fundamental para la realización del derecho a una alimentación y nutrición adecuadas; ya que gran parte de la

\footnotetext{
${ }^{47}$ M. Lagarde, Los cautiverios de las mujeres: madresposas, monjas, putas, presas y locas, México, UNAM, 2003, p. 363.

${ }^{48}$ Vid. F. L. Schieck Valente, "Hacia la completa realización del derecho humano a una alimentación y nutrición adecuadas”, FIAN Internacional, versión electrónica http://www.fian.org/fileadmin/media/publications/Hacia_realizaci on_DHaA_nutricion.pdf.
}

malnutrición sufrida por mujeres y niñas en el mundo actual es consecuencia directa de la violencia y de la discriminación estructural que sufren $^{49}$.

Para M. Cordero la denominada privatización de las mujeres con sus hijos e hijas (de la madremujer) influye necesariamente en la distinta concepción que se tiene de las niñas y de los niños incluso en aquellos casos y contextos en los que el trabajo infantil constituye una relidad cotidiana $^{50}$. Así, por ejemplo, en su investigación sobre las niñas trabajadoras en México, la antropológa B. Leyra Fatou se encontró con una división sexual del trabajo de las niñas con respecto a los niños trabajadores en Ciudad de México $^{51}$. En este sentido, considera necesario reconocer la intersección "edad" y "género" si se quiere evitar caer en un sesgo interpretativo por dejar fuera alguno de los elementos que configuran las desigualdades como, entre otros, el uso del tiempo, el uso del dinero, la diferente realización de trabajos fuera del ámbito familiar y la asignación inequitativa de tareas domésticas.

\footnotetext{
${ }^{49}$ Así, circunstancias como la malnutrición de las mujeres, el bajo peso al nacer, la malnutrición infantil, los transtornos de desarrollo en edad infantil y sus directas consecuencias sobre la vida adulta se deben en gran medida al hecho de que a las mujeres se les deniega la oportunidad de estudiar, de controlar sus cuerpos y sus propias vidas, de estar bien nutridas, de elegir cuándo y con quién desean casarse y tener hijos; Ibídem, p. 9.

${ }^{50}$ Vid. M. Cordero Arce, Hacia un discurso emancipador de los derechos de las niñas y de los niños, cit., p. 338.

${ }^{51}$ Vid. B. Leyra Fatou, Las niñas trabajadoras. El caso de México, cit., p. 276.
} 
Cuadernos Electrónicos de Filosofía del Derecho

Lo cierto es que tanto niñas como niños trabajan fuera de sus hogares, pero el trabajo en el hogar es mucho más intenso para las niñas. Esta invisibilidad doméstica de las mujeres y también de las niñas se da en un grado menor en los espacios públicos donde trabajan niños y niñas. Pero a pesar de ello se "ven" mucho menos que los niños. Ello explicaría en parte que las niñas están más controladas que los niños ${ }^{52}$. Si bien, según esta antropóloga, se da una cierta mitigación de la desigualdad de género entre niños y niñas en el espacio público con respecto al espacio doméstico.

Igualmente existe una problemática específica que afecta a los derechos de las niñas en el ámbito de la justicia penal juvenil, tal y como han señalado E. Bodelón y M. Aedo. Según estas investigadoras ni los derechos de las niñas ni las violaciones de derechos que sufren las niñas son idénticos con respecto a los niños ${ }^{53}$. Específicamente, el sistema penal juvenil refuerza con frecuencia la desigualdad de género. Así, las menores infractoras son víctimas de una violencia estructural en las que se las relega socialmente y las mantiene en una posición desventajosa.

\footnotetext{
${ }^{52}$ Ibídem, p. 276.

${ }^{53}$ Vid. E. Bodelón González y M. Aedo Rivera, "Las niñas en el Sistema de Justicia Penal", en Anales de la Cátedra Francisco Suárez (2015) no 49, p. 220-221.
}

Así, mientras que el sistema de justicia penal juvenil es el que sigue controlando fundamentalmente a los sujetos varones; la censura social de los comportamientos de las niñas sigue siendo ejercida por otras instancias sociales. Según estas investigadoras, las jóvenes son tratadas de forma diferente en el sistema penal juvenil como consecuencia de la existencia de un doble estándar de comportamiento. Y además las jóvenes tienen más posibilidades de experimentar la sanción o censura moral mediante mecanismos de control formal o informal por conductas tales como la conducta sexual, fugarse de casa, etc. En cuanto a las chicas jóvenes internadas en el sistema no sólo penal juvenil sino también en centros de protección o atención de menores, se puede detectar la centralidad que ocupa el factor de "la sexualidad" en la definición de "chicas problemáticas"54 que hacen los servicios sociales.

Estas autoras consideran que sería ingenuo negar que las chicas no son vulnerables a la explotación masculina $^{55}$. Sin embargo la mejor manera de evitar o paliar las relaciones de explotación y desigualdad que sufren las chicas no pasa por estigmatizarlas o negar su sexualidad. De ahí que cualquier intervención que pretenda eliminar la desigualdad de género en el ámbito de la justicia

\footnotetext{
${ }^{54}$ Ibídem, p. 228.

${ }^{55}$ Ibídem, p. 229.
} 


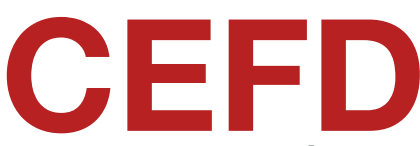

Cuadernos Electrónicos de Filosofía del Derecho

de menores tendría que reconocer la naturaleza de la discriminación específica que sufren las niñas y desarrollar sus derechos desde una perspectiva que tenga en cuenta su identidad como sujetos de derechos. En definitiva, se trataría de "dejar de ver" a los grupos socialmente en desventaja como sujetos pasivos o víctimas y empezar a verlos como personas, sujetos de derecho, para desde allí poder resolver sus problemáticas.

Por ello, se está pensando en la necesidad de "dar un espacio a las chicas para definir sus problemas" ${ }^{56}$ y una herramienta muy útil para ello sería el de la aplicación del concepto o estrategia de "empoderamiento" en las medidas que se les vayan a aplicar. Se trata de facilitar a estas jóvenes recursos a partir de los cuales puedan abordar sus necesidades, pero teniendo en cuenta que estas necesidades están definidas por su posición de género.

Dando un paso más, habría que apuntar que si bien ha habido avances en el acceso de las niñas y jóvenes a sus derechos; cuando las desigualdades obedecen a razones estructurales es preciso adoptar la perspectiva de la "interseccionalidad" para poder incluir distintos factores junto a los de "género" y "edad". Estos factores serán muy diversos, pero si atendemos a las cuestiones "étnicas" y

${ }^{56}$ Ibídem, p. 234. "culturales", la relación de interdependencia de muchas mujeres y niñas con respecto a los grupos sociales o étnico-culturales a los que pertenecen va a afectar decisivamente a la realización de sus derechos y darán lugar a formas diferentes de discriminación que las niñas acaban sufriendo de forma individualizada. Por ello, la discriminación “interseccional"57 permitirá hacer frente a los aspectos estructurales, multifactoriales y complejos que dan lugar a un trato desigual y discriminatorio en las niñas y a un difícil o inexistente acceso a sus derechos.

De indudable interés en este sentido en el ámbito de los derechos de las niñas y jóvenes es el hecho de que cada vez más las agencias de las Naciones Unidas y los Organismos Internacionales están centrando sus esfuerzos en llevar a cabo un trabajo conjunto de denuncia y de propuestas que acerque las esferas de las niñas y las mujeres como ámbitos conexos y complementarios que

${ }^{57}$ Se tiene interés en profundizar en un trabajo posterior sobre las posibilidades de un análisis desde esta óptica de la discriminación "interseccional" en la cuestión de los derechos de las niñas y jóvenes. Si bien, por razones obvias no puede abordarse esta perspectiva de la "interseccionalidad" con un mayor detenimiento en este artículo. Sobre este tipo de análisis son interesantes, entre otros, los siguientes trabajos: M. Barrère Unzueta, "La interseccionalidad como desafío al Mainstreaming de género en las políticas públicas", en Revista Vasca de Administración Pública (2010) no 87-88, p. 225-252; M. Barrère Unzueta y D. Morondo Taramundi, "Subordinación y discriminación interseccional: elementos para una teoría del derecho antidiscriminatorio", Anales de la Cátedra Francisco Suárez (2011) $\mathrm{n}^{\mathrm{o}}$ 45, 15-42; M. J. Añón Roig, "Principio Antidiscriminatorio y determinación de la desventaja", en ISONOMÍA (2013) no 39, p. 127-157. 


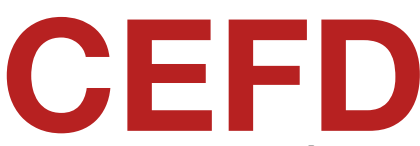

Cuadernos Electrónicos de Filosofía del Derecho

son. Así como el hecho de que incluyan la referida perspectiva "intersectorial" en sus textos normativos.

Concretamente, se han adoptado de forma conjunta la Recomendación General número 31 del Comité para la Eliminación de la Discriminación contra la Mujer y La Observación General número 18 del Comité de los Derechos del Niño sobre las prácticas nocivas (14 de noviembre de 2014) ${ }^{58}$. Más especficamente, ambos Comités reconocen que las prácticas nocivas afectan a mujeres adultas bien sea de manera directa o bien debido al impacto a largo plazo de las prácticas a las que se las sometió cuando eran niñas, o de ambas maneras.

Por su parte, el Comité para la Eliminación de la Discriminación contra la Mujer y Comité de los Derechos del Niño señalan que las prácticas nocivas están profundamente arraigadas en las actitudes sociales según las cuales se considera a las mujeres y a las niñas inferiores sobre la base

\footnotetext{
58 En su apartado II.5 (4/29) se señala que "La presente recomendación u observación general conjunta deberá ser compatible con las recomendaciones y observaciones generales pertinentes publicadas por los Comités, en particular la recomendación general núm. 19 sobre la violencia contra la mujer, y la observación general núm. 8 sobre el derecho del niño a la protección contra los castigos corporales y otras formas de castigos crueles o degradantes, y la observación general núm. 13 sobre el derecho del niño a no ser objeto de ninguna forma de violencia, del Comité de los Derechos del Niño. El contenido de la recomendación general núm. 14 sobre la circuncisión femenina, del Comité para la Eliminación de la Discriminación contra la Mujer, se actualiza mediante la presente recomendación u observación general conjunta.
}

de "funciones esterotipadas". Igualmente, subraya la dimensión de género del fenómeno de la violencia respecto a la cual las actitudes y estereotipos por razón de sexo, los desequilibrios de poder, las desigualdades y la discriminación acaban por perpetuar la existencia generalizada de prácticas que suponen violencia o coacción. En definitiva, según el Comité de Derechos del Niño "la discriminación por razón de sexo o de género se entrecruza con otros factores que afectan a las mujeres y a las niñas, en particular aquellas que pertenecen o se percibe que pertenecen a grupos desfavorecidos y que, por tanto, corren un mayor riesgo de ser víctimas de prácticas nocivas" $(4 / 29)$.

Por tanto, para ambos Comités, "las prácticas nocivas se fundamentan en la discriminación por razón de sexo, género y edad" y a menudo se "han justificado invocando costumbres y valores socioculturales y religiosos". En general, las prácticas nocivas suelen ir asociadas a graves formas de violencia o son en sí mismas una forma de violencia contra las mujeres y las niñas. En este sentido, las prácticas nocivas más prevalentes y más documentadas son: la mutilación genital femenina, el matrimonio infantil o forzoso, la poligamia, los delitos cometidos por motivos de honor y la violencia por causa de la dote $(5 / 29)$.

Hay otras muchas prácticas nocivas que están también estrechamente relacionadas con los 


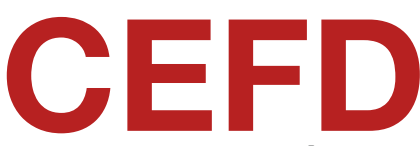

Cuadernos Electrónicos de Filosofía del Derecho

papeles asignados a cada género $\mathrm{y}$ con los sistemas de relaciones de poder patriarcales. Así, por ejemplo: el abandono de niñas (vinculado al trato y atención preferente que se presta a los niños varones); infanticidio e incesto; exámenes de virginidad y prácticas conexas; restricciones dietéticas extremas, incluso durante el embarazo (tabúes alimentarios); ritos iniciáticos violentos; la pobreza y exclusión de las niñas viudas; prácticas en aras de la belleza o de aumentar las posibilidades de matrimonio; prácticas para proteger a las niñas de un embarazo precoz o del acoso sexual (planchado de los senos) (5/29).

Como se ha señalado antes, si bien las causas de todas estas prácticas nocivas y de otras discriminaciones que sufren las niñas son estructurales y multifactoriales, los efectos los sufren de forma individualizada. A lo que habría que añadir que el daño que todas estas prácticas produce en las niñas y en las mujeres sobrepasa las consecuencias físicas y mentales inmediatas y, a la larga, produce el efecto de menoscabar y anular el ejercicio de sus derechos. Además tales prácticas suponen una negación de su dignidad, su integridad, su desarrollo físico, psíquico y moral, su salud, y su educación.

Por otro lado, pese a los esfuerzos en combatir todas estas y otras prácticas contra los derechos de las niñas que se han llevado a cabo en los últimos años, el número de niñas afectadas sigue siendo alto y puede que esté aumentando, tal y como refleja esta Recomendación conjunta (8/29).

Una práctica que no se visibiliza plenamente en nuestras sociedades es la de la incidencia de la violencia de género en la infancia y adolescencia. En el caso del Estado español, esta realidad ha sido denunciada por el Comité de Naciones Unidas para la Eliminación de la Discriminación contra la Mujer, en su sesión $n^{\circ}$ 61, al revisar el séptimo-octavo informe sobre el cumplimiento por España de la CEDAW. En este Informe, el Comité manifiesta su preocupación por el número de casos de niños y niñas asesinados por "padres violentos durante el ejercicio de su derecho de visita", .

Al respecto debe quedar claro que existe un derecho de los niños y niñas a una vida libre de violencia de género. En este sentido, parece que este derecho comienza a ser asumido en varias leyes de reciente aprobación, por lo que resulta oportuno recoger algunas de las reflexiones sobre la problemática de los niños y niñas como

${ }^{59}$ Concretamente, en su sesión $n^{\circ} 61$ el Comité examinó el séptimo-octavo informe sobre el cumplimiento por España de este Tratado. Una preocupación agravada por el injustificado incumplimiento por parte del Estado español de la decisión de la CEDAW de 16 de julio de 2014 en la que se condenaba al Estado por no proteger a Angela Gonzáles y su hija, a la que el maltratador asesinó en 2003 en una de las visitas establecidas y que a pesar de las denuncias de la víctima a su exmarido en 30 ocasiones por amenazas y agresiones no se habían interrumpido (CEDAW/C/58/D/47/2012, Comunicación $n^{\circ}$ 47/2012)- Por su parte, el Ministerio de Sanidad, Servicios Sociales e Igualdad no incorporó en los datos estadísticos sobre violencia de género a las víctimas mortales menores de edad hasta el año 2013. 


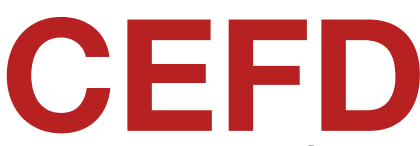

Cuadernos Electrónicos de Filosofía del Derecho

víctimas directas e indirectas de la violencia de género en el contexto del sistema jurídico español.

De entrada, se han producido avances tanto en lo que respecta a la protección y mejora de la información a las víctimas en el ámbito procesal como en lo que se refiere a la protección de los menores. Concretamente, se han ampliado las cautelas y se ha concedido una protección especial para los menores en virtud de las modificaciones llevadas a cabo por la Ley del Estatuto de la víctima del delito y las Leyes de protección de infancia, ambas de $2015^{60}$. A este respecto, resulta oportuno recoger algunas de las reflexiones que P. Reyes Cano realiza en su interesante investigación sobre los menores como víctimas de la violencia de género en el ámbito de la relación de pareja ${ }^{61}$. En este sentido, señala que “se trata de una 'violencia extendida' y que los que siempre acaban sufriendo de esa extensión de la violencia son los hijos e hijas que viven bajo el

\footnotetext{
${ }^{60}$ En este sentido, la Disposición Final $3^{\text {a }} .1$ de la L.O. 8/2015, de modificación del sistema de protección a la infancia y a la adolescencia, ha modificado el art. 1.2 de la L.O.1/2004: "Por esta ley se establecen medidas de protección integral cuya finalidad es prevenir, sancionar y erradicar esta violencia y prestar asistencia a las mujeres, a sus hijos menores y a los menores sujetos a tutela, o guarda y custodia, víctimas de esta violencia”.

61 Vid. P. Reyes Cano, "Menores y Violencia de Género" en Anales de la Cátedra Francisco Suárez (2015) nº 49, p. 182.
}

mismo estado de tensión y de alerta que su madre" ${ }^{, 62}$.

Es fundamental dar visibilidad a las violencias a las que los hijos e hijas han estado y están expuestos en las situaciones de violencia vividas por mujeres ${ }^{63}$. Ello permitirá comprender el impacto tan negativo que estas vivencias de violencia suponen en el bienestar y desarrollo de los niños y las niñas; e igualmente facilitará el cambio en las sensibilidades sociales y, a la larga, obtener respuestas desde las políticas públicas, la Administración y la Justicia.

Una de estas respuestas legislativas ha sido sin duda la citada Ley 4/2015, de 27 de abril, reguladora del Estatuto de la víctima (que ha entrado en vigor el 28 de octubre de 2015) ${ }^{64}$. Concretamente, el Estatuto de las víctimas del delito garantiza derechos procesales y extraprocesales de las víctimas incluyendo algunas disposiciones específicas que afectan a las víctimas de violencia de género. Dentro del concepto de víctima indirecta se encuadran los y

${ }^{62}$ Ibídem, p. 182. Puede consultárse también: Informe del Grupo de Trabajo de Investigación sobre la infancia víctima de la violencia de género, aprobado por el Observatorio Estatal de Violencia sobre la Mujer (8 de noviembre de 2011).

${ }^{63}$ Vid. P. Reyes Cano, "Menores y Violencia de Género", cit., p. 184.

${ }^{64}$ Ley que se adapta a el Convenio de Estambul de 15 de mayo de 2011 del Consejo de Europa sobre Prevención y Lucha contra la violencia contra las mujeres y la violencia doméstica y que traspone además las directivas de la Unión Europea sobre esta materia (en particular, la Directiva 2012/29/UE, de 25 de octubre DOUE-L-2012-82192-). 
Cuadernos Electrónicos de Filosofía del Derecho

las menores que viven en entornos de violencia de género, por todas las alteraciones que la exposición a la violencia supone para su desarrollo. A pesar de esta indudable mejora, hubiera sido muy clarificador que la Ley 4/2015 hubiera establecido una distinción conceptual entre, por un lado, los menores víctimas de violencia doméstica $\mathrm{y}$, por otro, los menores víctimas de violencia de género $^{65}$. Y ello porque, como es sabido, constituyen realidades muy distintas, con causas y consecuencias también diferentes.

Más allá de la protección procesal de niños y niñas víctimas directas o indirectas de la violencia de género, se han producido reformas puntuales por las también citadas Ley Orgánica 8/2015, de 22 de julio, y la Ley 26/2015, de 28 de julio de modificación del sistema de protección a la infancia y la adolescencia ${ }^{66}$. Concretamente en esta nueva normativa se entiende que la ${ }^{65}$ Vid. P. Reyes Cano, "Menores y Violencia de Género", cit., p.
196.

\footnotetext{
${ }^{66}$ Así en la Exposición de Motivos (VI), de la Ley Orgánica $8 / 2015$, de 22 de julio, señala que si bien "cualquier forma de violencia ejercida sobre un menor es injustificable. Entre ellas, es singularmente atroz la violencia que sufren quienes viven y crecen en un entorno familiar dónde está presente la violencia de género". Concretamente, continúa el legislador, "esta forma de violencia afecta a los menores de muchas formas, (...), condicionando su bienestar y su desarrollo; (...) causándoles serios problemas de salud; (...), convirtiéndolos en instrumento para ejercer violencia y dominio sobre la mujer. Y, finalmente, favoreciendo la transmisión intergeneracional de estas conductas violentas sobre la mujer por parte de sus parejas o ex parejas. La exposición de los menores a esta forma de violencia, los convierte también en víctimas de la misma".
}

protección contra la violencia de género es uno de los principios de actuación de los poderes públicos en relación con los menores (art. 6 de la Ley 26/2015, que modifica el art. 11 de la LO. 1/1996 de Protección Jurídica del Menor). Asimismo el artículo 7 de la Ley 26/2015 (que modifica el art.12 de la L.O 1/1996) establece que "cuando los menores se encuentren bajo la patria potestad, tutela, guarda o acogimiento de una víctima de violencia de género o doméstica, las actuaciones de los poderes públicos estarán encaminadas a garantizar el apoyo necesario para procurar la permanencia de los menores, con independencia de su edad, con aquélla, así como su protección, atención especializada y recuperación".

En este sentido, es importante la modificación que la referida D.F. $3^{\mathrm{a}}$ de la L.O. 8/2015, ha hecho de los artículos 65 y 66 de la L.O.1/2004. Así, en el caso de que el juez no adopte algunas de las medidas de suspensión de la patria potestad, custodia, régimen de visitas, estancia, relación o comunicación con los menores, deberá pronunciarse en todo caso sobre la forma en las que se ejercerá, adoptando las medidas necesarias para garantizar la seguridad, integridad y recuperación de los menores y de la mujer y teniendo que realizar un seguimiento periódico de su evolución. Si bien esta modificación no 
Cuadernos Electrónicos de Filosofía del Derecho

constituye una protección extra ${ }^{67}$, al menos se está obligando en todos los casos a los jueces a analizar la situación del menor víctima y a estudiar cómo se van a ejercer las funciones de la patria potestad por el inculpado de violencia de género, admitiendo la posibilidad de llevar a cabo un seguimiento sobre su evolución. Por último, la consideración de los menores como víctimas directas de la violencia de género propiciará la asunción por parte de los juzgados de violencia sobre la mujer de "competencias directas" con respecto a la violencia de género ejercida contra menores.

\section{Conclusiones}

Como se apuntaba en la introducción de este artículo, más de 25 años después de la promulgación de la Convención sobre los Derechos del Niño de las Naciones Unidas, se hace ineludible hacer balance de lo que ha sido sin duda un progreso importante en la concepción de los derechos de los niños. Pero ha llegado también el momento de plantear críticamente tanto el discurso de los derechos del niño, tal y como quedó recogido en la Convención, como las dificultades que a lo largo de los años nos seguimos encontrando. Razón por la que es

${ }^{67}$ Vid. P. Reyes Cano, "Menores y Violencia de Género", cit., p. 197. necesario reflexionar sobre cuáles podrían ser las causas y los motivos de las carencias y limitaciones que ha evidenciado este instrumento internacional.

En el marco de la Convención sobre los Derechos del Niño y de las legislaciones nacionales que aparecieron después, el principal esfuerzo en torno a los derechos de la infancia y de la adolescencia ha estado dirigido fundamentalmente a garantizar que niños y niñas tengan y puedan disfrutar de sus derechos. Sin querer restar importancia a tan relevante cuestión, no podemos dejar de subrayar el descuido --u olvido-- de las realidades sociales y culturales en medio de las cuales se desenvuelven "otras infancias" que se quedaron en los márgenes de la Convención, que no encajan en la concepción homogénea y dominante de la infancia allí recogida.

Las exigencias de no discriminación del artículo 2 de la Convención, cuando señala que los derechos reconocidos en la misma se disfrutarán sin distinción alguna por motivo de raza, color, sexo, origen nacional o social, etc., se hacen eco de algunas diferencias y diversidades culturales y sociales de la infancia, pero resultan a todas luces insuficientes. Desde la perspectiva de la sociología de la infancia se pueden distinguir diversas concepciones de infancia, las cuales van intrínsecamente unidas a otras realidades 
Cuadernos Electrónicos de Filosofía del Derecho

culturales y otras variables como las de la etnicidad, clase y género. En este sentido, para estas corrientes críticas, la definición legal y singular de "niño" es un instrumento muy limitado que deja fuera esas otras formas de ser niño o niña en el mundo y con ello, dificulta que las respuestas del derecho se adapten a la diversa realidad en la que viven muchos niños y niñas. Por tanto, si trabajamos hacia una mejor comprensión de la condición social de la infancia, de las diversas infancias, podremos sentar unas bases firmes para la implementación de sus derechos.

En relación con esto, es preciso concienciarse de cómo pueden derivarse algunos efectos perversos en el contexto de los Estados democráticos del bienestar, cuyas políticas de protección y de los derechos de los niños están fundamentalmente articuladas en una concepción cultural homogénea de la infancia. Y ello, entre otras razones, porque el indicador legal de que un niño o niña "esté solo o abandonado" se basa en considerar que la auténtica infancia se relaciona con la vida familiar, doméstica, en la que niños y niñas son cuidados por los adultos. Olvidando con ello que algunos de estos menores son justamente esas otras infancias que viven al margen de la concepción dominante de infancia, desconectados de sus familias y que posiblemente viven bajo su propia responsabilidad y ocupándose de sí mismos.

Resulta además ineludible incoporar una decidida perspectiva de género en el discurso de los derechos de los niños, tal y como viene siendo demandando por muchas y muchos expertos. Todos ellos se hacen eco de la realidad social, económica y cultural diferenciada y en muchos casos, discriminatoria que sufren las niñas en la familia, en la salud, en la educación, en el trabajo, en el ámbito de la justicia juvenil, etc. Concretamente, la especificidad de la discriminación que sufren las niñas es consecuencia, por un lado, de su pertenencia al grupo social de los menores de edad y, por otro, de su pertenencia al grupo social de las mujeres. En muchos contextos sociales y culturales, las niñas y adolescentes pueden verse sometidas a una mayor discriminación porque no son percibidas como potenciales sujetos-ciudadanos.

Desde una perspectiva internacional es indudable el avance que ha supuesto en el ámbito de los derechos de las niñas el hecho de que cada vez más las agencias de las Naciones Unidas y los Organismos Internacionales están centrando sus esfuerzos en llevar a cabo un trabajo conjunto de denuncia y de propuestas que acerque las esferas de las niñas y las mujeres como ámbitos conexos y complementarios que son. Igualmente en alguno de sus textos normativos más recientes han 
Cuadernos Electrónicos de Filosofía del Derecho

incluido una perspectiva "interseccional" que va a permitir hacer frente a algunos de los aspectos estructurales que dan lugar a las diversas formas de discriminación y trato desigual con las niñas y a un difícil o imposible acceso a sus derechos. En este sentido, se han adoptado de forma conjunta la Recomendación General número 31 del Comité para la Eliminación de la Discriminación contra la Mujer y La Observación General número $18 \mathrm{del}$ Comité de los Derechos del Niño sobre las prácticas nocivas (14 de noviembre de 2014). En particular, ambos Comités reconocen que las prácticas nocivas afectan a mujeres adultas bien sea de manera directa o bien debido al impacto a largo plazo de las prácticas a las que se las sometió cuando eran niñas, o de ambas maneras. Como se ha destacado a lo largo de este artículo, es cierto que las causas de todas estas prácticas nocivas y de otras discriminaciones que sufren las niñas son estructurales y multifactoriales. Ahora bien, los efectos los sufren las niñas y jóvenes de forma individualizada. Y a la larga puede además menoscabar y/o anular el ejercicio de sus derechos. Sin restar importancia al hecho de que tales prácticas suponen, en sí mismas, una negación de su dignidad, de su integridad, de su desarrollo físico, psíquico y moral, de su salud y de su educación.

La concienciación generalizada y una reflexión seria sobre -al menos-- las cuestiones aquí planteadas nos permitirá, entre otras cosas, una mejor comprensión de la infancia. Con estas bases podremos re-pensar la infancia y subsanar aquellas carencias y limitaciones que presenta la Convención en aras de una mejora de los derechos de todos los niños y niñas. De ahí que no baste con aplicar y/o implementar los derechos del niño sino que es necesario "traducirlos", esto es, hacerlos compatibles con las realidades, visiones y prácticas de manera contextualizada, teniendo en cuenta cada situación particular de niños $\mathrm{y}$ niñas. En definitiva, se debería ampliar la comprensión de los derechos de los niños y niñas, más allá de su protección y cuidado y dar un paso más que nos permita su percepcion como sujetos sociales plenos y diferenciados. Para ello se debe, desde luego, comenzar por conseguir que los niños y las niñas vivan en unas condiciones sociales dignas desde las que puedan adquirir la posibilidad y tambien la responsabilidad de ejercer sus derechos. 
Cuadernos Electrónicos de Filosofía del Derecho

\section{REFERENCIAS BIBLIOGRÁFICAS:}

Añón Roig, M. J., "Principio Antidiscriminatorio y determinación de la desventaja", en ISONOMÍA (2013) no 39, p. 127-157.

Barrère Unzueta, M., "La interseccionalidad como desafío al Mainstreaming de género en las políticas públicas", en Revista Vasca de Administración Pública (2010) $\mathrm{n}^{\mathrm{o}}$ 87-88, p. 225-252.

Barrère Unzueta, M. y D. Morondo Taramundi, "Subordinación y discriminación interseccional: elementos para una teoría del derecho antidiscriminatorio", Anales de la Cátedra Francisco Suárez (2011) no 45, 1542.

Bernuz, M. J., "El derecho a ser escuchado: el caso de la infancia en conflicto con la norma”, en Derechos y Libertades (2015) no 33 , p. 67-98.

Bernuz, M. J., De la protección de la infancia a la prevención de la delincuencia, Zaragoza, Justicia de Aragón, 1999.

Bodelón González, E. y M. Aedo Rivera, “Las niñas en el Sistema de Justicia Penal", en Anales de la Cátedra Francisco Suárez (2015) no 49, p. 219-236.

Bosisio, R., “Children's Rights to be Heard: What Children Think", International Journal of Children's Rights (2012) 20, p.141-155.

Bueno Abad, J. R. y F. J. Mestre Luján, "La protección de menores no acompañados", en Revista Alternativas. Cuadernos de Trabajo Social (2006) no 14 p. 155-170.
Calvo García, M., "La protección del menor y sus derechos", Derechos y Libertades (1993) no 2, p. 177-99.

Calvo García, M. y J. Guilló Jiménez (coords.), Globalización y derechos de la infancia y la adolescencia, Zaragoza, LSJUZ_Centro de Investigación y Documentación de la Infancia y Adolescencia, 2007.

Campbell, T.D., "The Right of the Minor: as Person, as Child, as Juvenil, as Future Adult", en Ph. Alston, S. Parker, J. Seymour (eds.), Children Rights and the Law, Oxford, Oxford Clarendon Press, 1992, p. 1-23.

Campoy Cervera, I., "Notas sobre la evolución en el reconocimiento y la protección internacional de los derechos de los Niños" en Derechos y Libertades no 6 (1998), p. 279327.

Campoy Cervera, I., La fundamentación de los Derechos de los Niños. Modelos de reconocimiento y protección, Madrid, Dykinson, 2006, p. 977-1002.

Campoy Cervera, I., "El desarrollo de un modelo de protección de los niños en el siglo XIX", en en G. Peces-Barba, edtr., Historia de los Derechos Fundamentales, Madrid, Dykinson, Tomo III, Volumen II, Libro 1, Cap. XXX , 2007, p. 471- 532.

Cordero Arce, M., "Towards an Emancipatory Discourse of Children Rights" en International Journal of Children's Rights (2012) 20, p. 365-421.

Cordero Arce, M., Hacia un discurso emancipador de los derechos de las niñas y los niños, Lima, IFEJANT, 2015. 
Cuadernos Electrónicos de Filosofía del Derecho

Eekelaar, J., "The importance of thinking that chidlren have rights", en Ph. Alston, S. Parker, J. Seymour (eds.), Children Rights and the Law, Oxford, Oxford Clarendon Press, 1992, p. 221-235.

Eekelaar, J., "The Interests of the Child and the Child's Wishes: The Role of Dynamic SelfDeterminism", en International Journal of Family Law (1994) no 8, p. 42-61.

Fanlo, I. (comp.), Derecho de los niños. Una contribución teórica, 1a ed., México D.F., Fontamara, 2004.

Fernando, J. L., “Children's Rights: Beyond the impasse", en The Annals of the American Academy of Political and Social Science (2001) 575, p. 8-24.

Fortin, J., Children's Rights and the Developing Law, 2 ${ }^{\mathrm{a}}$ ed., Cambridge, CUP, 2005.

Freeman, M. D.A., “Taking Children's Rights More Seriously", en Ph. Alston, S. Parker, J. Seymour (eds.), Children Rights and the Law, Oxford, Oxford Clarendon Press, 1992, p. 5271 ;

Gaitán, L. y M. Liebel, Ciudadanía y Derechos de Participación de los Niños, Madrid, Universidad Pontificia de Comillas-Editorial Síntesis, 2011.

Garzón Valdés, E., “Desde la modesta propuesta de J. Swift hasta las casas de engorde. Algunas consideraciones acerca de los derechos de los niños", en Doxa (1994) no 15-16, p. 731-743.

Hierro, L., "El niño y los derechos humanos", en I. Fanlo (comp.), Derechos de los niños. Una contribución teórica, 1ํㅗㄹ., México D.F., Fontamara, 2004, p. 177-197.

Lagarde, M., Los cautiverios de las mujeres: madresposas, monjas, putas, presas y locas, México, UNAM, 2003.

Leyra Fatou, B., Las niñas trabajadoras. El caso de México, Madrid, La Catarata, 2012.

Liebel, M., "Sobre el interés superior de los niños y la evolución de sus facultades", Anales de la Cátedra Francisco Suárez (2015) no 49, p. 43-61.

MacCormick, N., "Los derechos de los niños: una prueba para las teorías del derecho", en Derecho Legal y Socialdemocracia. Ensayos sobre filosofía jurídica y política, trad. M. Lola González Soler, Madrid, Tecnos, 1982, p. 129-137.

Marks, S. y A. Clapham, International Human Rights Lexicon, 1믈 ed., Oxford, Oxford University Press, 2005.

Mayall, B., "The sociology of childhood in relation to children's rights", The International Journal of Children's Rights (2000) 8, p. 243-259.

Minow, M., "Rights for the next generation: A feminist approach to children's rights" en Harvard Women's Law Journal (1986) vol 9, p. 1-24.

Minow, M., “Children's Rights. Where we've been, and where we're going", en Temple Law Review (1995) 68, p. 1573-1584.

Mosconi, G., "Prefazione”, en A. Sbraccia e Ch. Scivoletto (eds.), Minori Migranti: Diritti $e$ Devianza. Ricerche Socio-Giuridique sui 
Cuadernos Electrónicos

de Filosofía del Derecho

minori non accompagnati, Torino, L'Harmattan Italia, 2004, p. 5-10.

O’Neill, O., “Children's Rights and Children's Lives", en Ph. Alston, S. Parker, J. Seymour (eds.), Children Rights and the Law, Oxford, Oxford Clarendon Press, 1992, p. 24-42.

Olsen, F., “Children's Rights: Some feminist approaches to the United Convention on the Rights of the Child", en International Journal of Law and the Family (1992) 6, p.192-220.

Pérez Crespo, M.J. y V. Hernández Solís, “Territorio globalizado: ¿realidad o ficción vista desde la infancia en la inmigración?, en M. Calvo García y J. Guilló Jiménez (coords.), Globalización y derechos de la infancia y la adolescencia, Zaragoza, LSJUZ_Centro de Investigación y Documentación de la Infancia y Adolescencia, 2007, p. 37-58.

Picontó Novales, T., La protección de la infancia: Aspectos sociales y jurídicos, Zaragoza, Egido Editorial, 1996.

Picontó Novales, T., En las fronteras del derecho. Estudio de casos y reflexiones generales, Madrid, Dykinson, 2000.

Picontó Novales, T., "Presupuestos y avance de los mecanismos jurídicos de protección de la infancia en el siglo XIX", en G. PecesBarba, edtr., Historia de los Derechos Fundamentales, Madrid, Dykinson, Tomo III, Volumen II, Libro 1, Cap. XXX , 2007, p. 533568.

Picontó Novales, T., "Religious Freedom and Protection of the Right to Life in Minors: A Case Study", en M. Maclean and J. Eekelaar (ed.), Managing Family Justice in Diverse Societies, Hart Publishing/Oñati International Institute for The Sociology of Law, 2013, p. 137-151

Ravetllat Ballesté, I., "El interés superior del niño a la luz del nuevo artículo 2 de la Ley Orgánica 1/1996, de 15 de enero", en http://laleydigital.laley.es/

Ravetllat Ballesté, I., Aproximación histórica a la construcción sociojurídica de la categoría infancia, Valencia, Editorial Universitat Politècnica de València, 2015.

Reyes Cano, P., "Menores y Violencia de Género" en Anales de la Cátedra Francisco Suárez (2015) no 49, p. 181-217.

Ronfani, P., "I Diritti dei bambini: vecchie e nuove questioni", en Sociologia del Diritto (2013) no 2, p. 117-122.

Rubio, A., "La igualdad de género: Los derechos de las niñas", en Ruth Mestre Mestre (coord.), Mujeres, derechos y ciudadanía, Valencia, Tirant lo Blanch, 2008, p. 245-285.

Sbraccia, A. y Ch. Scivoletto (eds.), Minori Migranti: Diritti e Devianza. Ricerche SocioGiuridique sui minori non accompagnati, Torino, L'Harmattan Italia, 2004.

Valente, F. L. Schieck, "Hacia la completa realización del derecho humano a una alimentación y nutrición adecuadas", FIAN Internacional, versión electrónica en http://www.fian.org/fileadmin/media/publ ications/Hacia_realizacion_DHaA_nutricion. pdf. 
Cuadernos Electrónicos

de Filosofía del Derecho

Van Bueren, G., The Internacional Law on the Rights of the Child, Dordrecht, Martinus Nijhoff, 1995.

Van Bueren, G., Child Rights in Europe. Convergence and divergence in Judicial Protection, Strasbourg, Council of Europe, 2007.

Villagrasa Alcaide, C. e I. Ravetllat Balleste (coords.), Por los derechos de la infancia y de la adolescencia. Un compromiso mundial desde el derecho de participación en el XX aniversario de la Convención sobre los Derechos del Niño, 1aㅡ ed., Barcelona, Bosch, 2009.

Villagrasa, C., "Derechos de la Infancia y Adolescencia: Hacia un sistema legal", en Anales de la Cátedra Francisco Suárez (2015) no 49, p. 17-41.

Wellman, C., An Approach to Rigths. Studies in the Philosophy of Law, Oxford, Oxford University Press, 1995.

Wills Rivera, L., "La incorporación progresiva de los niños y niñas adolescentes a la ciudadanía activa", en C. Villagrasa Alcaide e I. Ravetllat Balleste (coords.), Por los derechos de la infancia y de la adolescencia. Un compromiso mundial desde el derecho de participación en el XX aniversario de la Convención sobre los Derechos del Niño, Barcelona, Bosch, 2009, p. 113-140.

Yac Huís, J. M., “Parlamento Guatemalteco para la niñez y adolescencia: garantizando la participación ciudadana justa", en C. Villagrasa Alcaide e I. Ravetllat Balleste (coords.), Por los derechos de la infancia y de la adolescencia. Un compromiso mundial desde el derecho de participación en el XX aniversario de la Convención sobre los Derechos del Niño, Barcelona, Bosch, 2009, p. 191-202. 
Cuadernos Electrónicos de Filosofía del Derecho

FUENTES DOCUMENTALES:

ARARTEKO, Situación de los menores extranjeros no acompañados en la CAPV, Ararteko, 2005.

CDN, Observación General no 14 del Comité de los Derechos del Niño, del 29 de mayo de 2013, sobre el derecho del niño a que su intéres superior sea una consideración general.

CEDAW, Decisión de 16 de julio de 2014, por la que se condena al Estado por no proteger a Angela Gonzáles y su hija (CEDAW/C/58/D/47/201, Comunicación no 47/2012).

CEDAW, Observaciones finales sobre los informes periódicos séptimo y octavo combinados de España, (CEDAW/C/ESP/CO/7-8), de 29 de julio de 2015.

CEDAW/CDN: Observación General número 18 del Comité de los Derechos del Niño/Recomendación General número 31 del Comité para la Eliminación de la Discriminación contra la Mujer, sobre las prácticas nocivas (14 de noviembre de 2014).

CONSEJO DE EUROPA, Convenio sobre Prevención y Lucha contra la Violencia contra las Mujeres y la Violencia Doméstica, Estambul, 15 de mayo de 2011.

NU, Protocolo facultativo de la Convención sobre los Derechos del Niño relativo a la venta de Niños, la Prostitución Infantil y la Utilización de Niños en la Pornografía, aprobado mediante resolución de 25 de mayo de 2000 (A/RES/54/263)

NU, Protocolo facultativo de la Convención sobre los Derechos del Niño relativo a la Participación de Niños en los Conflictos Armados, aprobado mediante resolución de 25 de mayo de 2000 (A/RES/54/263)

NU, Protocolo facultativo de la Convención sobre los Derechos del Niño relativo a un Procedimiento de Comunicaciones, aprobado mediante resolución de 19 de diciembre de 2011 (A/RES/66/138)

NU-CDN, Observación General no 14 del Comité de los Derechos del Niño, del 29 de mayo de 2013, sobre el derecho del niño a que su intéres superior sea una consideración general.

NU-Relator Especial del Derecho a la Alimentación (A. Eide), Informe sobre la realización del derecho a la alimentación y el derecho a permanecer libre de hambre, 1999 (E/CN.4/Sub.2/1999/12, 28 Junio 1999).

NU-Relator Especial sobre el derecho a la alimentación (0. de Schutter), Informe sobre la realización del derecho a la alimentación y el derecho a permanecer libre de hambre: Los derechos de la mujer y el derecho a la alimentación, Informe presentado al Consejo de Derechos Humanos el 24 de diciembre de 2012 (A/HRC/22/50) .

OBSERVATORIO ESTATAL DE VIOLENCIA SOBRE LA MUJER, Informe del Grupo de Trabajo de Investigación sobre la infancia víctima de la violencia de género, Madrid, 8 de noviembre de 2011. 
Cuadernos Electrónicos de Filosofía del Derecho

OIT, Convenio sobre la prohibición de las peores formas de trabajo infantil y la acción inmediata para su eliminación de 1999 (C 182), con fecha de entrada en vigor de 19 de noviembre de 2000.

UE, Directiva 2012/29/UE, de 25 de octubre, DOUE-L-2012-82192.

UNICEF-Centro de Investigaciones Innocenti, Las reformas legales y la implementación de la Convención sobre los derechos del niño,
Florencia, Centro de Investigaciones Innocenti de UNICEF, 2008. 